\title{
Time of Flight Measurements of Unirradiated and Irradiated Nuclear Graphite under Cyclic Compressive Load
}

DOI:

10.1016/j.jnucmat.2016.12.044

\section{Document Version}

Accepted author manuscript

Link to publication record in Manchester Research Explorer

\section{Citation for published version (APA):}

Bodel, W., Atkins, C., \& Marsden, B. (2017). Time of Flight Measurements of Unirradiated and Irradiated Nuclear Graphite under Cyclic Compressive Load. Journal of Nuclear Materials, 487, 50-67.

https://doi.org/10.1016/j.jnucmat.2016.12.044

\section{Published in:}

Journal of Nuclear Materials

\section{Citing this paper}

Please note that where the full-text provided on Manchester Research Explorer is the Author Accepted Manuscript or Proof version this may differ from the final Published version. If citing, it is advised that you check and use the publisher's definitive version.

\section{General rights}

Copyright and moral rights for the publications made accessible in the Research Explorer are retained by the authors and/or other copyright owners and it is a condition of accessing publications that users recognise and abide by the legal requirements associated with these rights.

\section{Takedown policy}

If you believe that this document breaches copyright please refer to the University of Manchester's Takedown Procedures [http://man.ac.uk/04Y6Bo] or contact uml.scholarlycommunications@manchester.ac.uk providing relevant details, so we can investigate your claim.

\section{OPEN ACCESS}




\title{
Time of Flight Measurements of Unirradiated and Irradiated Nuclear Graphite under Cyclic Compressive Load
}

\author{
W. Bodel, C. Atkin, B. Marsden \\ Nuclear Graphite Research Group, The University of Manchester \\ Health and Safety Laboratory, Buxton
}

\begin{abstract}
The time-of-flight technique has been used to investigate the stiffness of nuclear graphite with respect to the grade and grain direction. A loading rig was developed to collect time-of-flight measurements during cycled compressive loading up to $80 \%$ of the material's compressive strength and subsequent unloading of specimens along the axis of the applied stress. The transmission velocity (related to Young's modulus), decreased with increasing applied stress; and depending on the graphite grade and orientation, the modulus then increased, decreased or remained constant upon unloading. These tests were repeated while observing the microstructure during the load/unload cycles. Initial decreases in transmission velocity with compressive load are attributed to microcrack formation within filler and binder phases. Three distinct types of behaviour occur on unloading, depending on the grade, irradiation, and loading direction. These different behaviours can be explained in terms of the material microstructure observed from the microscopy performed during loading.
\end{abstract}

\section{Introduction}

Graphite is and has been used extensively as a moderator within nuclear reactors ever since the first artificial nuclear reactor in Chicago achieved criticality in 1942, through to prospective Generation IV reactor designs. In the United Kingdom, two graphite grades, with very different microstructures, have been used in this moderator role: Pile Grade A (PGA), used in the first generation Magnox reactors; and Gilsocarbon, used in the succeeding Advanced Gas-cooled Reactors (AGRs). Samples of these two grades were used in this work which studied the influence of microstructure on stiffness, however the findings are applicable to newer graphite grades being developed for use in Generation IV High Temperature Reactors (HTRs) and Molten Salt Reactors (MSRs).

Examples of the microstructures of PGA and Gilsocarbon are shown in Figure 1 and Figure 2 respectively. The microstructures of these graphite grades can be considered as consisting of three separate phases: binder, filler and porosity [1]; and the most significant difference between the two grades is the difference between the filler material. PGA was manufactured using "needle-shaped" coke particles as the filler material; elongated grist particles which were by-products of the cracking process during petroleum manufacture [2]. Due to the method of billet manufacture, the "needleshaped" coke preferentially aligns during the extrusion process prior to baking, yielding an anisotropic final product. The anisotropic microstructure of PGA results in strongly anisotropic material properties [3], which are generally quoted as "with grain" (measured along the axis of extrusion), or "against grain" (measured along one of the axes perpendicular to the axis of extrusion); a convention which is used throughout this paper, with grain directions of specimens logged prior to testing. In contrast, Gilsocarbon utilised spherical coke particles which were derived from Gilsonite, a naturally occurring asphalt after which the graphitised material is named [4]. In addition, prior to baking, Gilsocarbon was pressed into shape rather than extruded which, when combined with the spherical particles, resulted in a near-isotropic material. 
The other two phases to consider when examining graphite microstructures are the binder and porosity. The binder is a pitch-flour-particle mix which is blended with sized coke particles after their calcination and prior to baking. Porosity in nuclear-grade graphite takes three forms. Firstly, the calcination of coke particles prior to mixing leads to the formation of narrow lenticular shaped cracks within the particles, which are still clearly observable in the final graphitised microstructure. These cracks run circumferentially in Gilsocarbon coke filler particles, and along the long axis of PGA grist filler particles. Secondly, the baking process results in the evolution of volatiles from the pitch-particle mix, resulting in large, globular gas-evolution porosity existing within the binder and around coke particles. Lastly, while the graphitisation process leads to a far more ordered material at a crystal level than exists in prior stages in the manufacturing process, the final product is far from a perfect graphite crystal; the difference in density between an ideal graphite material $\left(\sim 2.27 \mathrm{~g} \mathrm{~cm}^{-3}\right)$, and the skeletal density of the polycrystalline product used in nuclear applications is considered microporosity. One of the sources of this closed microporosity results from cracks which are formed during the thermal contraction of cooling after the graphitisation process, known as Mrozowski cracks [5]. The skeletal density of Gilsocarbon is $\sim 2.00 \mathrm{~g} \mathrm{~cm}^{-3}$, with bulk density around $1.82 \mathrm{~g} \mathrm{~cm}^{-3}$; a result of the open porosity within the material [6]. The heterogeneous nature of artificial graphite results in differences in measured values across samples. The differences in material properties between the grades are documented [7].

There is a reduction in Young's modulus when test specimens of polycrystalline graphite are placed under tensile or compressive stress [8]. It is also well observed that the non-linear stress-strain behaviour becomes progressively more linear as the test material becomes irradiated, which is attributed to pinning of dislocations in basal planes [9]. This work follows the evolution in transmission velocity (i.e. the variable used to calculate dynamic Young's modulus) of virgin Gilsocarbon and virgin and irradiated PGA when placed under compressive load, and examining the changes to the microstructure in order to better understand the relationship between microstructure and unloading behaviour.

\section{Experimental}

\subsection{Materials}

Compressive specimens of unirradiated Gilsocarbon and PGA were prepared as cubes of dimensions $(40 \times 40 \times 40) \mathrm{mm}^{3}$ to allow for testing across all three axes. The PGA samples used for this work were cut from an unused moderator brick for the Oldbury Magnox reactor. Gilsocarbon samples were prepared from an unmachined billet of Gilsocarbon provided by EDF; though the designated reactor for this batch of material is unknown, however this work is aimed at understanding loading behaviour rather than obtaining engineering data. Irradiated PGA specimens originate from spacer material taken from a non-thermocoupled installed set assembly. The reactor mean core irradiation during their discharge was $29,835 \mathrm{MWd} / \mathrm{te}$. No dosimetry calculations specific to the spacer were available, however using data for the adjacent position an irradiation temperature of $325^{\circ} \mathrm{C}$ and a dose of 3.5 dpa can be estimated from MCBEND calculations. These samples were irradiated in carbon dioxide and therefore their densities are reduced because of radiolytic oxidation [10]. The original size of the source material limited the dimensions of the irradiated specimens to cubes of $(18 \times 18 \times 18) \mathrm{mm}^{3}$.

Small samples of each material of dimensions $(15 \times 9.5 \times 6) \mathrm{mm}^{3}$ where the span of the sample is $15 \mathrm{~mm}$ were also prepared for loading in a microtester. The top surfaces of the samples were polished to allow for images to be captured clearly during loading. Because of the strong anisotropy of the properties of PGA, the grain directions of each PGA specimen were noted during machining to enable measurements with and against grain to be carried out where appropriate.

\subsection{Apparatus}


A Panametrics Model 5800 pulser/receiver was used in conjunction with two Olympus $1 \mathrm{MHz}$ V103RM right angled microdot/BNC contact transducers to generate and receive longitudinal ultrasonic pulses. The pulser/receiver was controlled by a LeCroy WaveRunner $64 \mathrm{Xi} 600 \mathrm{MHz}$ digital oscilloscope, with Sonatest Sonagel W couplant gel used to provide appropriate signal propagation. Samples were compressed in a servo-hydraulic Mayes 500 universal testing machine with a selfaligning spherical platen using the apparatus shown in Figure 3 to prevent loading to the transducers during testing. Transducers were attached to the rig using a triggered G-clamp. Strains were measured through the use of Tokyo Sokki Kenyujo $120 \Omega$ FLA 6-11 strain gauges (gauge factor 2.1) attached to the test specimen using M-Bond 200 strain gauge adhesive. The lack of extended experimental durations, humidity or elevated temperatures during these experiments permits the use of a fast-acting cyanoacrylate adhesive instead of a more environmentally resilient resin adhesive. No incidences of debonding were experienced.

A Deben MICROTEST module (shown in Figure 4) was used to compress the small specimens. This was used in conjunction with an Olympus LEXT OLS4000 3D Confocal Laser Scanning Microscope to capture images of samples under load. No direct measurements of strain were recorded on the loading of small specimens due to the limited space available to take such measurements, though strain can be estimated by the position of the loading platens.

\subsection{Methodology}

Time of flight data were recorded manually using a through transmission mode, subtracting the transmission time between the steel plates. Time of flight was measured with the oscilloscope as the distance between the wave packet which makes up the detected signal and the outbound signal. To reduce broadening effects, time of flight measurements were made using the beginning of the detected waves rather than the peaks, defined as $10 \%$ of the amplitude of the peak under consideration.

Unirradiated samples of PGA and Gilsocarbon machined to $(40 \times 40 \times 40) \mathrm{mm}^{3}$ were loaded to $~ 80 \%$ of the material compressive strength in increments of $5 \mathrm{kN}$; equivalent to increments of $3.13 \mathrm{MPa}$ of compressive stress, with strains recorded. At each $5 \mathrm{kN}$ increment, a constant load was applied and time of flight measured. Samples were cycled between the maximum load and a minimum of $5 \mathrm{kN}$ up to three times. The compressive strengths used to determine the $80 \%$ target load were estimated from the failure of a test specimen (of similar geometry) of each material immediately prior to testing (34 MPa for PGA and $90 \mathrm{MPa}$ for Gilsocarbon).

Irradiated specimens were loaded in a similar fashion, however in increments of $0.5 \mathrm{kN}$; $(1.54 \mathrm{MPa})$ on smaller $(18 \times 18 \times 18) \mathrm{mm}^{3}$ specimens.

In the second series of experiments using the MICROTEST module, samples machined to $(15 \times 9.5 \times 6) \mathrm{mm}^{3}$ were loaded to various compressive loads and then held under constant load while micrographs were collected using a $5 \times$ objective lens. A series of 21 images were collected for stitching together at each load to ensure the full $15 \mathrm{~mm}$ span of the test specimen was imaged. Based on the results from the initial time of flight/compression results on the large specimens, applied loads for this testing followed the following methodology:

- Load to $10 \%$ of predicted failure.

- Unload to zero load (in practice, near zero to prevent unwanted sample movement).

- Load to $75 \%$ of predicted failure in five increments.

- Unload to zero in two increments.

- Load to failure, collecting images at every $10 \%$ above $75 \%$ of predicted failure. 


\section{Results and Discussion}

Table 1 shows the mean mechanical property values measured on the samples. Dynamic Young's modulus was calculated as a function of density and time of flight [11].

\subsection{Time of flight of unirradiated material}

As expected, the samples exhibit a non-linear stress-strain relationship when loaded, as indicated in Figure 5, where a sample of semi-isotropic Gilsocarbon graphite has been cyclically loaded along an arbitrary $x$-axis (in this case the pressing direction of the billet). The curve for the $y$-axis shows the expansion of the sample perpendicular to the loading direction with load. Data is presented for only two orthogonal axes since one pair of faces on the test specimen were dedicated to time of flight data collection, preventing strain measurements form being collected on the third (here the $z$-) axis. Load and strain data were collected rapidly $(50 \mathrm{~Hz})$ to reduce interpolation error; the points indicate when the loading was held constant and a time of flight measurement conducted. The sample recovers with the removal of the load, however a degree of permanent set is observed of around $0.2 \%$ strain as can be seen in Figure 5 with the removal of load. Subsequent unload/reload cycles to the same target load repeat the initial unload/reload cycle plotted without deviation. A Poisson's ratio of 2.2 can be determined from the initial axial and transverse strains. Prior to loading, the specimen had a density of $1839.3 \mathrm{~kg} \mathrm{~m}^{-3}$, after loading, the density was measured as $1840.8 \mathrm{~kg} \mathrm{~m}^{-3}$.

Young's modulus (given in Table 1) was calculated using the following equations:

$$
\begin{gathered}
E=\rho v_{l}^{2} \frac{(1-2 \mu)(1+\mu)}{(1-\mu)} \\
\mu=0.5\left(\frac{v_{l}^{2}-2 v_{t}^{2}}{v_{l}^{2}-v_{t}^{2}}\right)
\end{gathered}
$$

where $E$ is Young's modulus, $\rho$ is bulk density, $v_{l}$ is the transmission velocity of a $1 \mathrm{MHz}$ longitudinal pulse through a given test specimen, $\mu$ is Poisson's ratio and $v_{t}$ is the transmission velocity of a $1 \mathrm{MHz}$ transverse pulse through a specimen. Equation 1 for determining dynamic Young's modulus is provided in the ASTM standard C769-09 [12], while Equation 2 is the recommended method of calculating Poisson's ratio dynamically as detailed in the British Standard BS EN843-2:2007 [11].

Time of flight data are presented in the subsequent figures as longitudinal transmission velocity $\left(v_{l}\right.$, which as shown above in Equation 1 and Equation 2, is related to Young's modulus), against compressive stress. The reason for plotting transmission velocity rather than a calculated value of Young's modulus is that firstly it removes the complication of a reduced pulse traversal distance (i.e. increased density) with increased strain when plotting time of flight against stress; and secondly does not rely on an assumption of a constant Poisson's ratio or a measure of transverse pulse velocity with varying load (the latter enabling the calculation of the former however neither has been measured accurately here), both of which would be required in accurately plotting Young's modulus against stress. Transmission velocity is thus indicative of the Young's modulus of the material, however as previously raised, the main interest here is to understand the mechanisms involved in property changes rather than gather specific engineering data.

The time of flight measurements conducted at each of the points marked in Figure 5 are shown in Figure 6 and Figure 7 and show Gilsocarbon's transmission velocity parallel and perpendicular to the loading direction respectively. The reduction in transmission velocity with increased applied load is attributed to the formation and opening of cracks within the material microstructure, which increase the propagation time of the pulses through the medium accordingly. Subsequent removal of the load leads to the transmission velocity recovering and increasing with load removal, though not to the initial values, indicating permanent damage to the microstructure which is also demonstrated in the 
permanent set observed in the stress-strain curve in Figure 5. This recovery of transmission velocity is attributed to the closure of cracks opened during the loading process, improving coupling through the specimen. Axial transmission velocity decreases from approximately $2775 \mathrm{~m} \mathrm{~s}^{-1}$ at zero load to $2450 \mathrm{~m} \mathrm{~s}^{-1}$ at a compressive stress of $70 \mathrm{MPa}$; transmission velocity perpendicular to the loading axis reduces from $2775 \mathrm{~m} \mathrm{~s}^{-1}$ to $2675 \mathrm{~m} \mathrm{~s}^{-1}$ over the same load, demonstrating that the damage to the microstructure which delays the pulse traversal through the specimen is dependent on the load direction. An analysis of the microstructural changes that occur during loading will follow in section 3.3 during discussion of data collected with the MICROTEST apparatus.

Figure 8 shows the change in axial transmission velocity for PGA loaded with grain (parallel to the extrusion direction). Initial transmission velocity is just under $3000 \mathrm{~m} \mathrm{~s}^{-1}$, decreases non-linearly in a similar trend to Gilsocarbon to $2530 \mathrm{~m} \mathrm{~s}^{-1}$; however the recovery upon removal of the load is far smaller than that of Gilsocarbon. The process which governs the change in transmission velocity in PGA is therefore largely non-recoverable, unlike the partially-recoverable strain behaviour Gilsocarbon exhibits. It can be concluded from this that damage to the microstructure brought about by compression does not recover as is the case with Gilsocarbon. Since the only significant difference between the microstructures is the shape and orientation of the filler material, it is likely the spherical filler particles in Gilsocarbon respond to the loading in a more elastic fashion than the needle-shaped ones present in PGA. While all specimens were taken to failure after cyclic loading, the loads up to failure are not shown for Gilsocarbon. Time of flight equipment was removed from the test specimen prior to failure to reduce the likelihood of damage to this apparatus which may occur with the brittle failure of a Gilsocarbon specimen under $140 \mathrm{kN}$ of compressive load. PGA failures were far less energetic so time of flight measurements closer to failure could be collected without fear of damage to apparatus.

Compressing PGA against the grain direction demonstrates a different trend (Figure 9). Initial velocities are of the order of $2000 \mathrm{~m} \mathrm{~s}^{-1}$; the large variation in the initial stiffness depends on the grain orientation, thus illustrating the highly anisotropic nature of the material. As in the previous cases, the transmission velocity reduces as compressive load is applied. On unloading, the velocity does not increase back towards its initial value as is the case when loading and unloading Gilsocarbon, or remain fairly constant as is the case with PGA compressed along the with grain direction; instead, the velocity continues to drop, at a rate similar to that observed on initial loading. The following reload closely follows the unloading trend back towards the point at which maximum load was achieved whereupon it begins to decrease once more following the trend of the initial loading. This behaviour is extremely counter-intuitive. If a decrease in transmission velocity is indeed indicative of damage being induced within a specimen, possibly in the form of more/larger microcracks, then these data suggest that initial loading introduces damage (as is the case with Gilsocarbon and PGA with grain), but when this load is removed, the unloading process leads to even further damage being caused. Finally, re-loading the sample after this initial load-unload cycle pushes the sample state back to where it was when it was under load initially before the unloading began; the damage/recovery cycle appears to have been permanently reversed by the initial loading, as subsequent load-unload cycles follow the same path as the first unload and re-load. Explanations as to the reasons behind these data require a study of the microstructure during these loading conditions, which is what has prompted the second series of experiments presented.

In order to determine at what load the phenomena observed in Figure 9 starts to occur, a similar sample of PGA with the same grain orientation was cyclically loaded and unloaded to increasing maximum loads. Loads were increased and decreased in multiples of $5 \mathrm{kN}$, however the first load was to $10 \mathrm{kN}$ then unloaded, the second to $15 \mathrm{kN}$ and unloaded the third to $20 \mathrm{kN}$ and so on, to failure. The resulting stress-strain curve for the sample loaded against grain is shown in Figure 10, showing that each load cycle demonstrates an increased degree of residual strain upon unloading, but ultimately displaying similar characteristics to that of compressed Gilsocarbon (Figure 5). 
Figure 11 is the variation in transmission velocity with load recorded for PGA in an orientation similar to that of Figure 9, with the incremental loading described above. It is clear from these data that at higher compressive stresses, the curves follow similar paths to that shown in Figure 9; at low loads however, the behaviour is different. The initial plot to just $5 \mathrm{MPa}$ shows the decrease in transmission velocity as compressive load is added, but when it is removed the transmission velocity recovers to almost its original value. The second load to $\sim 10 \mathrm{MPa}$ also sees an increase in transmission velocity on unload, but does not recover as completely as the previous load cycle upon removal. As the maximum load of the load cycles increases, the tendency for the transmission velocity to return to its initial value is diminished, with velocities remaining constant upon load removal by around $12.5 \mathrm{MPa}$ as the maximum load of the cycle. Eventually the trend of a slowing transmission velocity on unloading becomes increasingly evident as the loading goes beyond $\sim 30 \%$ of failure. At very low stresses, the damage which governs transmission velocity is recoverable. At moderate stresses, this damage is permanent. At high stresses, the reversal of the recovery mentioned in the discussion of Figure 9 occurs. Figure 11 can therefore be divided into two regions, an initial region between 0 and $10 \mathrm{MPa}$ where the removal of low stresses do little in the way of permanent damage, resulting in the transmission velocity recovering; and a second region from around 15-20 MPa upwards where the removal of stress does not recover, and eventually leads to a downward trend on unloading if the initial load is high enough.

It is apparent from this that beyond a critical point in the compression of the specimen, damage to the sample becomes such that removal of the compressive load results in further damaging of the structure, which leads to the continued drop in transmission velocity observed. At low loads, the damage to the structure is minor enough for the material to return in a large part to its original arrangement. When more significant damage is inflicted on the specimen through higher compressive loading, after unloading the microstructure is considerably different to what it was prior to loading. Initial inspection of the similarity of the plots for Gilsocarbon's transmission velocity with compressive load, and the associated stress-strain curve could understandably lead one to propose the hypothesis that the same mechanism is responsible for both behaviours. The equivalent data presented for PGA suggest this is not the case: Firstly, at low load cycles the transmission velocity with load completely recovers whereas the stress-strain data over this range already demonstrates a degree of permanent set; secondly, the stress-strain behaviour at moderate loads is partiallyrecoverable, whereas the transmission velocity is completely non-recoverable; and lastly, at high load cycles, the two behaviours deviate entirely from each other.

\subsection{Time of flight of irradiated material}

A typical stress-strain plot of an irradiated specimen is shown in Figure 12. The loading curve is more linear than was the case for the unirradiated material, a well-documented characteristic of irradiated graphite specimens [13] which have embrittled due to the irradiation induced changes to the crystal structure. Compressive loading of irradiated PGA with grain (Figure 13) leads to a smaller reduction in transmission velocity which does not recover when the specimen is unloaded, thus showing similarities to its pre-irradiated counterpart (Figure 8). The irradiated specimens compressed perpendicular to the grain direction (Figure 14) show the initial decrease in transmission velocity with initial load, which recovers with the removal of the load, showing closer similarities to unirradiated Gilsocarbon than unirradiated PGA in this respect. This suggests that in addition to the linearization of the stress-stain relationship, the irradiation has an impact on the ability of the material microstructure to recover.

\subsection{Microstructural changes of unirradiated material}

Understanding of the behaviour of the observed changes to transmission velocity seen thus far can be attained from inspection of the microstructure of similar materials undergoing compression. 
Figure 15 shows micrographs of Gilsocarbon being compressed from essentially zero load to $75 \%$ of the expected failure $(2500 \mathrm{~N})$ and unloaded. Failure occurred at a subsequent compressive load slightly above $3000 \mathrm{~N}$. What is evident from the image series (particularly after comparing with the PGA grades being compressed under similar conditions), is how little the microstructure appears to change at this magnification up to the point of failure.

In the images leading up to $2000 \mathrm{~N}$ load shown in Figure 15, little variation in the microstructure can be detected by straightforward inspection. Beyond $2000 \mathrm{~N}$ however, cracks begin to propagate from the existing porosity within the structure, primarily from the lenticular circumferential cracks within the filler particles. Closer inspection on the difference between the top and middle image of Figure 15 show that a large number of thin cracks have formed, primarily within the various filler particles and from the edges of porosity as a result of the significant amount of load which has been applied to the specimen. The areas where cracks emerge are indicated on the first image for clarity. Comparison between the central image (at high load) and the bottom image, where the load has been largely removed shows that many of the new cracks which were visible at the higher load have now closed. This trait is not observed within PGA, and it is proposed that this is the origin of the differences in loading behaviour observed in the previous tests.

It was previously observed that transmission velocity through compressed Gilsocarbon reduces with increasing compressive stress, which can be attributed to the opening of voids within the microstructure observed here; in turn impeding the pulse transmission. Removal of the compressive load results in a recovery of the transmission velocity due to the closure of some of the newly opened cracks, however this recovery is only partial as the crack closure upon unloading is incomplete.

The behaviours observed have been attributed to microcracking within the microstructure, particularly within and around filler particles. Repeating the loading conditions carried out on the larger time of flight samples, it has been possible to observe crack formation during compression. In Gilsocarbon, multiple thin cracks appear throughout the microstructure, primarily within filler particles as extensions of their lenticular circumferential calcination porosity. When unloading the stressed test sample, many of the cracks close as the stress is removed, correlating with the decrease and subsequent increase in the transmission velocity measured during the time of flight tests.

The ability of the structure to recover and close some of the cracks which have opened is dependent on the material being compressed. Furthermore, the response of the filler particles in PGA under the compressive load is dependent entirely upon the filler particle orientation.

Observations with PGA now make it possible to understand the behaviour previously described in Figure 9 and Figure 11. It has been established that needle-coke PGA graphite gives different results depending on the relative orientation of the filler particles. Below $20 \%$ of the failure load, results are similar to those of Gilsocarbon, i.e. transmission velocity reduces with compressive stress and recovers to a large extent towards its original value prior to stressing when unloaded. Differences in behaviour occur when specimens are loaded beyond $20 \%$ of the failure load.

Beyond $20 \%$ of the failure load, the stress-strain behaviour of PGA is similar to that of Gilsocarbon, displaying non-linearity from the outset and demonstrating a degree of elastic recovery alongside some permanent setting. The behaviour of the transmission velocity beyond $20 \%$ however is dependent on the alignment of the coke particles. When PGA graphite is loaded parallel to the grain direction, a decrease in transmission velocity is observed, as with Gilsocarbon however upon unloading the transmission velocity remains constant. If loaded against grain, PGA exhibits identical behaviour with regards to transmission velocity, with the exception that as the load exceeds $20 \%$ of failure load, unloading appears to further reduce the transmission velocity. Subsequent reloading increases it back to its previous value, effectively reversing the transmission velocity-stress relationship. 
Figure 16 shows a sample of PGA cyclically loaded with grain. This magnified region clearly shows a large filler particle aligned along the grain direction (from left to right). As can be seen by the lack of variation between each of the three images, the filler particle remains unaffected by the compressive load, and this continues right up until the point of failure, the rigidity of the filler particle parallel to the preferential basal plane orientation being far larger than that perpendicular and thus ensuring the particle maintains its structure when orientated in this direction. Failure eventually takes place within the binder, around the filler particles which remain intact.

Figure 17 shows micrographs from the compression of PGA, this time compressed against grain. They show the extent of progressive damage which takes place during compression of PGA against grain. The extent of the damage done to the material is clear from the large numbers of cracks which appear in the central filler particle. By the final of the three images the large filler particle at the centre-right of the image is almost unrecognisable owing to the large numbers of cracks now present.

It is proposed that these cracks, and their response to loading and unloading are responsible for the behaviours demonstrated in Figure 6, Figure 8 and Figure 9. As the cracks brought about by compressive stress grow larger and more frequent, fewer points of contact between neighbouring phases will exist, resulting in an associated drop in transmission velocity observed (and thus a lower measure of dynamic Young's modulus). Whereas Gilsocarbon recovers from its cracking rather well, with many of the new cracks closing when the load is released, cracks formed in PGA tend to persist even after the damaging load has been removed. This would go some way to explain the tendency for the transmission velocity to remain constant when loads are removed if the microstructure has been damaged enough by the compressive load.

In Figure 18, the red arrows on the first image indicate positions where new cracking opens when compressive load is applied (shown in the middle image). The yellow arrows show regions of preexisting porosity which are closed during the compression. When the load is subsequently removed, the large amount of new porosity in the form of cracks opened by the initial compressive loading does not close, persisting as can be seen in the final image. The removal of the load does however reopen the porosity that was closed during the initial loading, thus increasing the porosity even further than was the case at the maximum load. The final image therefore contains the porosity which is closed by the deformation at high loads in addition to the extra porosity that was opened by the same load in the form of cracking. The reversal effect of the transmission velocity seen in Figure 9 is also explained by this; any subsequent reloading will close the original porosity once-more, yet the cracks brought about by the damage from the initial load do not change. The fact that this effect is not observed on the initial loading cycle (to a low maximum load before unloading) explains why the transmission velocity recovers during load cycles with low top loads in Figure 11 and progressively flattens as that maximum load increases, before reversing entirely at the highest load cycles.

Further evidence of this can be seen in the next image series of a different PGA sample being compressed against the grain. The region with the most prominent filler particle has been magnified and is shown in Figure 19. The grain direction runs vertically through the image. This filler particle is of similar size and shape as the particle in Figure 16, however this particle is aligned perpendicular to the axis of compression, not parallel to it. The significance of orientation can be easily seen; by the time $1000 \mathrm{~N}$ of compressive load is applied, the particle is dominated with cracks of varying sizes running vertically through its structure, parallel to the preferential alignment of graphite planes in the particle; in the with grain sample in Figure 16, no cracks are noticeable at this load. Where failure cracks tend to travel around filler particles in Gilsocarbon, with the particles themselves acting to absorb some of the energy, PGA filler particles compressed against grain collapse completely and the cracks within them contribute to the eventual failure. In this instance, the cracks resulting from the collapse of the large filler particle shown here connect with the tributary of cracks emanating from the binder region directly below the particle. With regards to the earlier discussion surrounding variable 
transmission velocity, the behaviour of the porosity as a result of this cyclic incremental loading (circled), widens during unloading.

The cracking behaviour within PGA is therefore different from Gilsocarbon, giving rise to the trends observed with regards to transmission velocity with the removal of the initially applied stress. The reason for this difference is primarily because the filler particles in PGA are highly anisotropic, unlike Gilsocarbon, where spherical filler particles are close to isotropic. The preferential alignment of the basal planes within the crystallites along the major axis of the filler particle leads to an increased stiffness of the filler particles along the major axis. This results in their increased resistance to deformation when compressive stress is applied along the with grain direction; in this instance, crack formation resulting from the applied loads occurs in the binder matrix, where the local rigidity is randomised compared to within the filler. The general lack of recovery from the cracking induced within the binder correlates with the reduced transmission velocity observed during the initial loading process not recovering during unloading as was the case with Gilsocarbon, where cracking occurring within spherical filler particles recovers well when the material is unloaded.

Increased strength along the long axis of the needle shaped filler particle is accompanied with weakness along the other two "against grain" axes. When PGA is compressed against grain, the filler particles are the source of much of the damage endured; the converse is the case when compressed with grain. Filler particles compressed against grain receive considerable damage even at comparatively low loads and this large amount of cracking perpetuates within the filler particle even after the load is removed. The further decrease in transmission velocity which is observed when unloading a specimen stressed against grain can be explained by the reopening of pre-existing porosity which was closed during the initial compression when the sample is eventually unloaded, while the cracks opened during the loading process remain open, thus increasing the total opened porosity within the microstructure when unloading. Reapplying load after this initial cycle simply closes once more the more responsive porosity which opened during unloading while doing no further damage to the filler material until loading exceeds that of the original loading and new damage occurs.

Incremental cyclic loading of PGA in both orientations showed that the deformation at low load cycles recovers to a far greater extent than the larger cracking which is observed at the higher load cycle.

By analysing micrographs from the loading cycles, it is possible to view the progressive crack formation quantitatively. Figure 20 illustrates the result from thresholding the image and calculating the total number of individual regions of porosity using the image processing software ImageJ using the technique previously discussed by Taylor [14]. The blue circles indicate the positions where micrographs are collected and it should be noted that the lines between these points are included to indicate the order of the points and are not indicative of estimates of porosity at given positions along the line. Figure 21 includes equivalent data for Gilsocarbon.

It is clear from these data that the analysis drawn from initial inspection is correct; loading of PGA with grain (i.e. along the axis of extrusion; the specimen shown in Figure 16) results in little to no change in the number of pores, that is right up until the loading approaches the point of failure. For the specimen loaded against grain (i.e. perpendicular to the extrusion axis; the specimen shown in Figure 19), even at lower loads adding compressive load results in significant crack formation. Critically, the second unloading phase (shown as a dashed grey line) does not close pores which have been opened during the damage induced by the loading. On the third and final load (to failure; a solid light grey line), pore frequency does not change until the load goes beyond the maximum load already experienced during the previous loading phase, at which point the growth in crack numbers continues along the same trajectory as was seen during that loading phase. By comparison, Gilsocarbon behaves much as has been interpreted so far by inspection, demonstrating a considerable ability to recover from compressive loading. 


\subsection{Microstructural changes of irradiated material}

PGA becomes embrittled with irradiation, and demonstrates a more linear stress-strain relationship and lower strain to failure than is observed prior to irradiation. Measurements of transmission velocity with load on these specimens suggests a greater degree of recovery than is the case with unirradiated material, but the embrittlement resulting from the irradiation means that any testing must be conducted over far smaller strains.

The image series in Figure 22 shows the response of an irradiated PGA sample compressed with grain. A large filler particle is visible and is marked by a red circle. As was the case for the virgin PGA compressed with grain, the filler particle undergoes very little cracking or deformation during the loading. What is different with irradiation however is how little occurs across the entire sample surface. Very little strain is observed throughout the compression. No visual indication can be derived from the images as to the imminent failure of the specimen; somewhere around $630 \mathrm{~N}$ in a very brittle fashion. The fast neutron irradiation in the reactor environment serves to stiffen the graphite structure, resulting in less observable strain and the embrittlement of the whole system. Under load, the material moves as three bulk plates, illustrated in the figure as separated by the blue lines, which also give the approximate location of the failure crack in the final image. The yellow arrows indicate the displacement of the three plates which move with the compression.

A significant change is noticed between the microstructure of the irradiated PGA compressed against grain and its non-irradiated counterpart. Figure 23 shows the case for irradiated PGA compressed against grain. Here, the filler particles remain intact throughout the compression unlike in the case of the virgin compression sample shown in Figure 17 or Figure 19, where the filler particles were the phase most affected by the compression. The filler particle circled in red in the first image for example shows little to no deformation within itself, with much of the movement taking place along various fault lines (marked in blue) as was the case with the unirradiated PGA compressed with grain. Plates between these lines twist and rotate as the sample is compressed, but very little strain between the fault lines is observed. A brittle failure takes place at slightly below $600 \mathrm{~N}$, with failure occurring through the binder matrix.

For unirradiated PGA specimens, the orientation and thus the behaviour of the filler particles determine the resulting transmission velocity under load. Fast neutron irradiation leads to embrittlement of the graphite and increases the Young's modulus. This leads to less crack formation within the filler particles, and an eventual lower strain to failure. For PGA, this prevents the behaviour observed in the unirradiated material from occurring; stiffer particles exhibit fewer cracks at low loads and as such accommodate less strain, reaching failure at comparatively low strain. The strain to failure values for the irradiated PGA tested were around $20 \%$ of those of the unirradiated PGA.

The irradiated PGA specimens here are embrittled and have also clearly been affected by around $20 \%$ weight loss. The irradiation stiffens the graphite crystals within the structure, as observed in the linearization of the stress-strain curve, while the oxidation weakens the material. These phenomena combine, resulting in the filler particles no longer being subject to the same collapse when loaded against grain as was the case prior to irradiation; the binder matrix cracks and fails before the filler material, which remains largely intact, regardless of whether the material is compressed with or against grain. It should be noted that although these specimens have also undergone oxidation during their time spent in reactor conditions, which may contribute to the property changes. It is likely however that the embrittlement observed is likely a result of the neutron irradiation damage rather than the oxidation [15].

\section{Conclusions}

A rig has been developed to obtain stress-strain data and enable the collection of time-of-flight data across two axes simultaneously during compressive loading. This has been used to cyclically 
compress coarse-grained nuclear graphite and simultaneously measure time of flight through the axis of compression which has produced different effects depending on:

- The filler material used as the aggregate particles in the bulk material; specifically the shape of the grist particles and their ability to recover from compressive stress.

- The alignment of any anisotropic filler particles with respect to the axis of loading, with particles deforming less when compressed along their stiffer axis.

- The response of the binder matrix, and the closing and opening of the porosity within it.

- The level of irradiation the material has undergone, with irradiated material becoming stiffer and failing in a more brittle fashion.

The differing behaviour described in the results has not previously been reported. By recreating the loading/unloading conditions from the rig with a microtester/microscope combination it has been possible to explain the counterintuitive behaviour observed with the time of flight measurements. Loading behaviour has previously been attributed to microcracking, however cracking behaviour on unloading has never previously been observed.

Table 1. Mechanical properties of cubic test specimens. For anisotropic material, // denotes measurements made parallel to the grain direction; $\perp$ denotes perpendicular to the grain. Poisson's ratio for PGA assumes a transversely isotropic material such that $\left(v_{12}=v_{13}\right)$ denotes loading parallel to the grain direction and $\left(v_{21}=v_{31}\right)$ and $\left(v_{23}=v_{32}\right)$ denote loading against grain measuring transverse strain with grain and against grain respectively.

\begin{tabular}{|c|c|c|c|}
\hline Property & $\begin{array}{l}\text { Unirradiated } \\
\text { PGA }\end{array}$ & $\begin{array}{l}\text { Irradiated } \\
\text { PGA }\end{array}$ & Gilsocarbon \\
\hline Density $/ \mathrm{g} \mathrm{cm}^{-3}$ & 1.72 & 1.41 & 1.83 \\
\hline Dynamic Young's modulus, $E_{D} / \mathrm{GPa}$ & $\begin{array}{l}/ 11.1 \\
\perp \quad 5.2\end{array}$ & $\begin{array}{l}/ / 2.5 \\
\perp \quad 6.5\end{array}$ & 12.4 \\
\hline Static Young's modulus, $E_{S} / \mathrm{GPa}$ & $\begin{array}{ll}/ / & 8.7 \\
\perp & 4.0\end{array}$ & 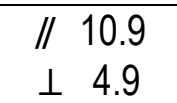 & 10.1 \\
\hline Anisotropy ratio & 2.13 & 1.92 & 1.02 \\
\hline Ratio $E_{S} / E_{D}$ & $\begin{array}{ll}/ & 0.78 \\
\perp & 0.77\end{array}$ & $\begin{array}{ll}/ & 0.87 \\
\perp & 0.75\end{array}$ & 0.81 \\
\hline $\begin{array}{c}\text { Dynamic Young's modulus (axially at highest } \\
\text { stress) / GPa }\end{array}$ & $\begin{array}{l}/ / 7.9 \\
\perp \quad 4.5\end{array}$ & $n / a$ & 9.6 \\
\hline $\begin{array}{l}\text { Dynamic Young's modulus (axially after stress) / } \\
\qquad \mathrm{GPa}\end{array}$ & $\begin{array}{l}/ / 8.0 \\
\perp 4.1\end{array}$ & $n / a$ & 11.1 \\
\hline $\begin{array}{l}\text { Compressive } \\
\text { strength / } \mathrm{MPa}\end{array}$ & $\begin{array}{l}/ / 32.2 \\
\perp \quad 31.5\end{array}$ & $\begin{array}{l}/ / 20.4 \\
\perp \quad 19.1\end{array}$ & 89.4 \\
\hline Strain at failure & $\begin{array}{l}/ / .6 \% \\
\perp \quad 2.5 \%\end{array}$ & 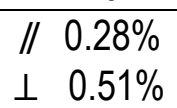 & $3.2 \%$ \\
\hline Poisson's ratio (from time of flight) & $v_{12} \quad 0.06$ & $n / a$ & 0.21 \\
\hline Poisson's ratio (from axial and transverse strain) & $\begin{array}{ll}v_{12} & 0.09 \\
v_{23} & 0.14 \\
v_{21} & 0.05 \\
\end{array}$ & $\begin{array}{ll}v_{12} & 0.30 \\
v_{21} & 0.12\end{array}$ & 0.22 \\
\hline
\end{tabular}




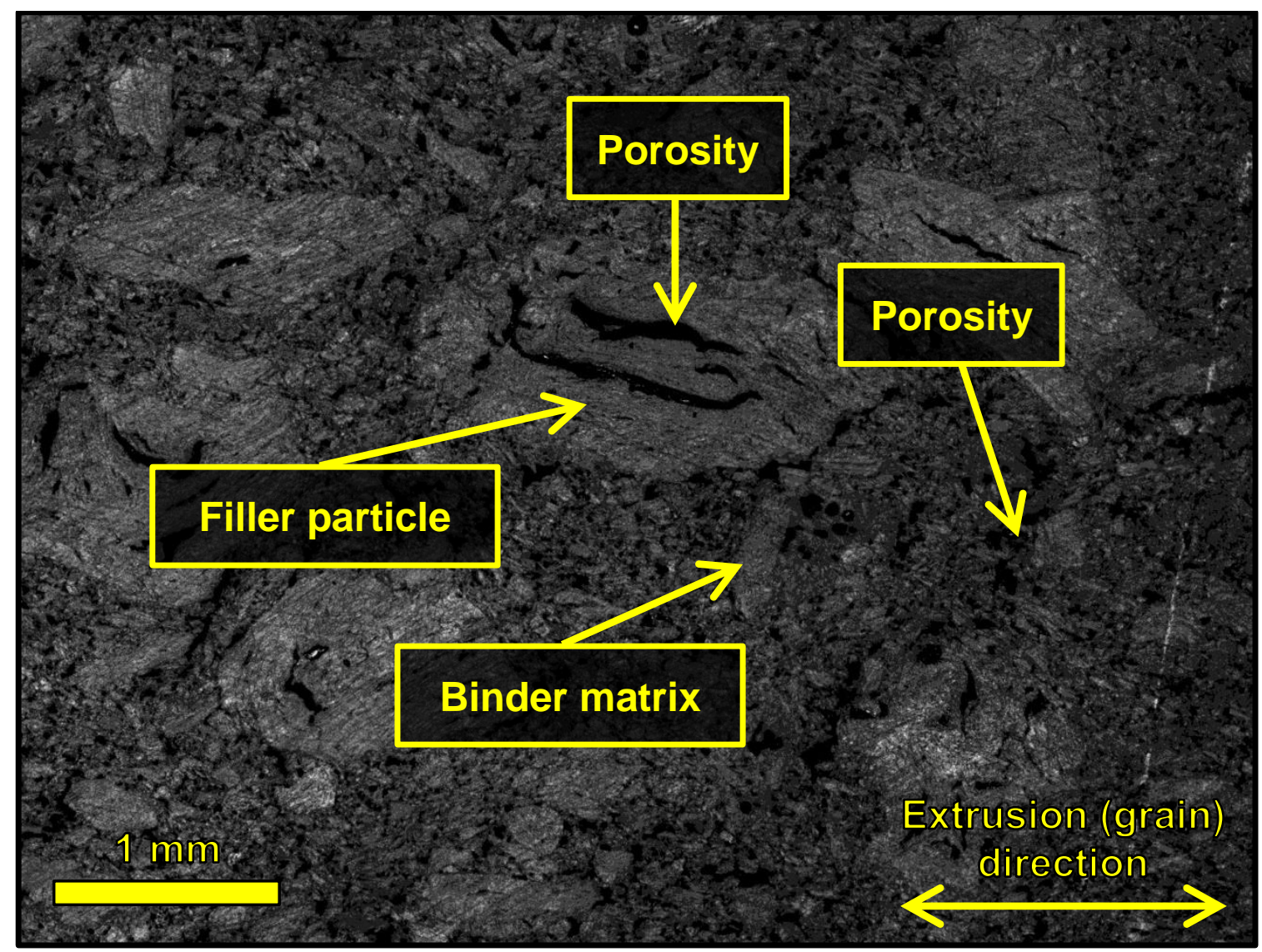

Figure 1. Microstructures of PGA graphite indicating common features. The extrusion direction is shown; left to right is considered "with grain" while up and down is referred to as "against grain". 


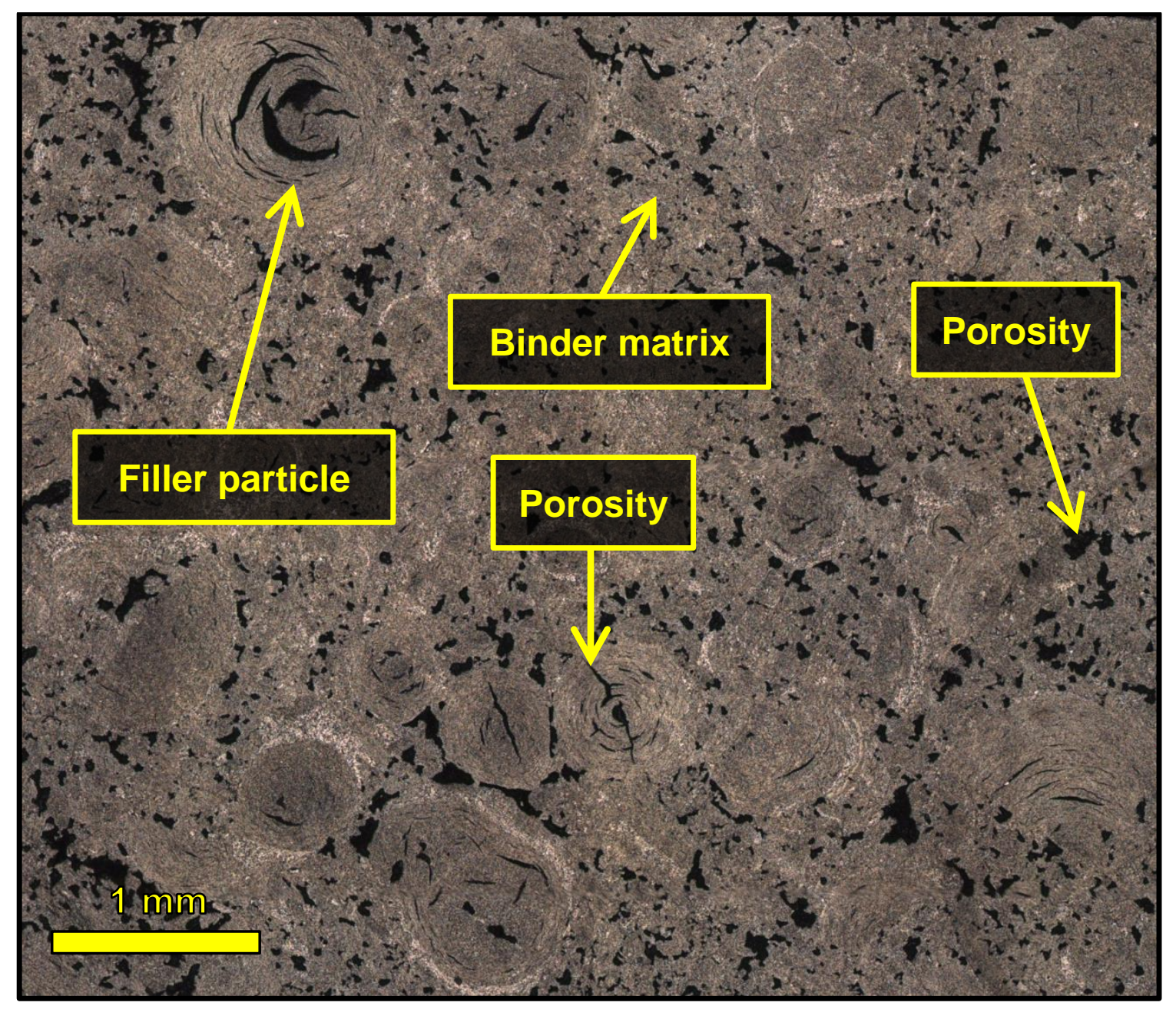

Figure 2. Microstructure of Gilsocarbon with equivalent features. Note the main difference between this and the PGA microstructure is the shape of the filler particles. 


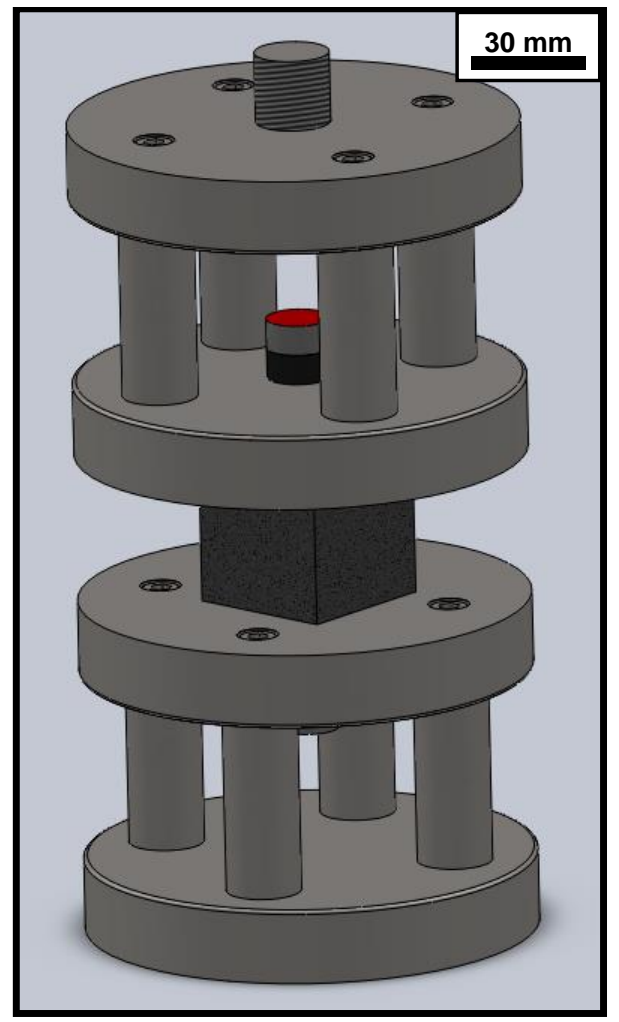

Figure 3. EN24 Steel rig design for measuring dynamic Young's modulus of $(40 \times 40 \times 40) \mathrm{mm}^{3}$ specimens under load without damaging the transducers. The screw thread attaches to a spherically aligning platen.

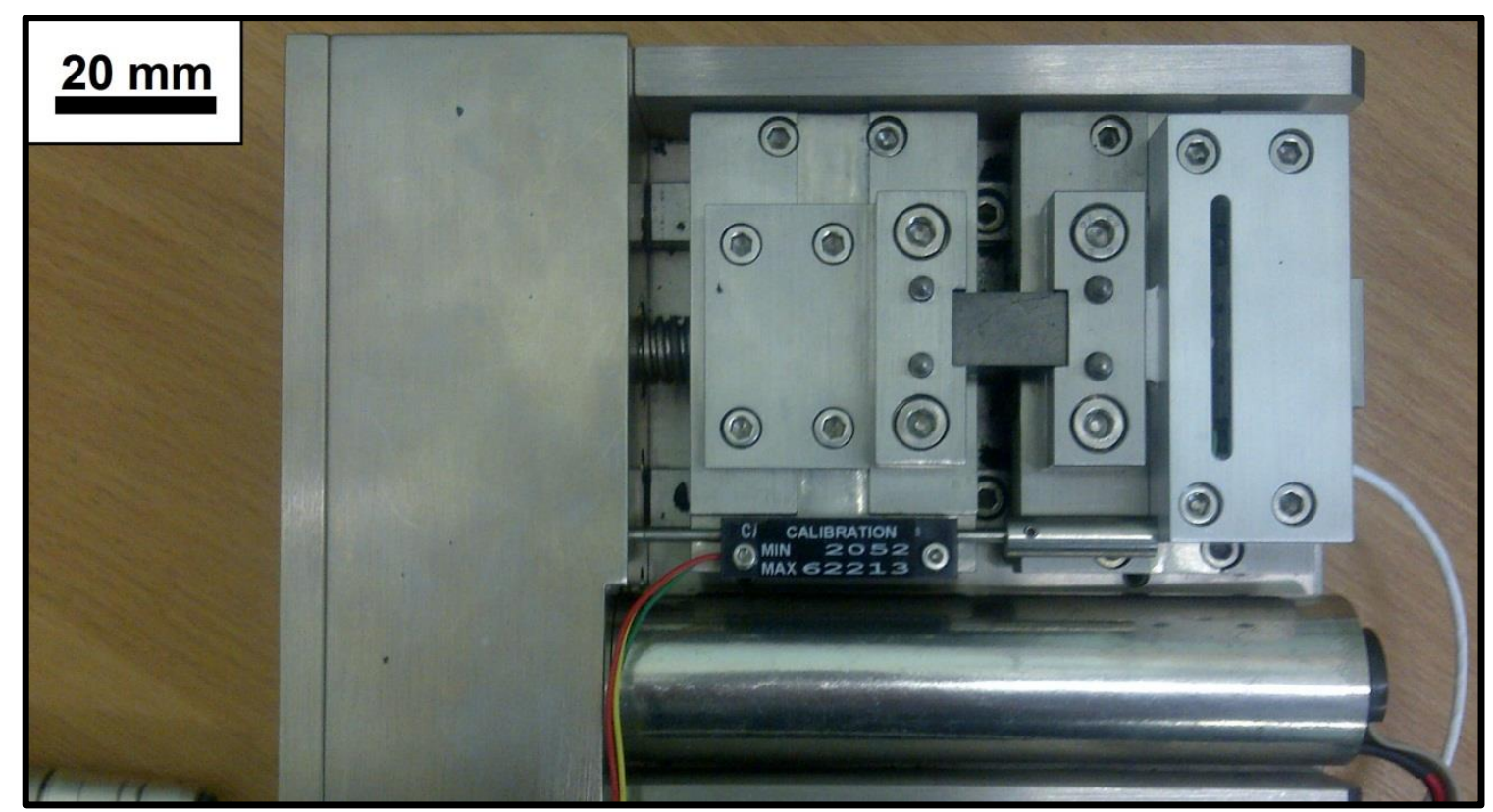

Figure 4. The Deben MICROTEST device used for small sample compression loaded with a typical graphite $(15 \times 9.5 \times 6) \mathrm{mm}^{3}$ test specimen. 


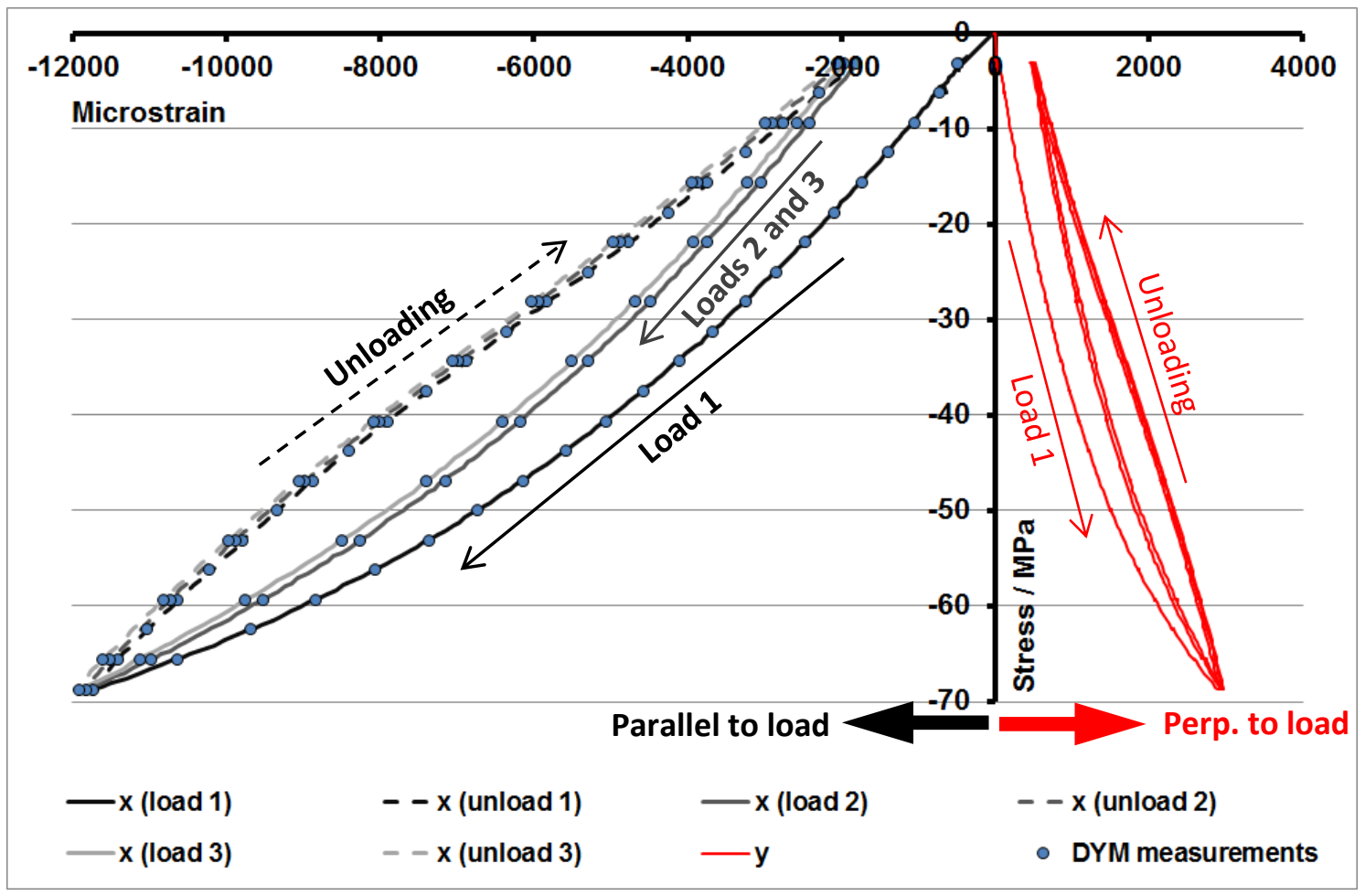

Figure 5. Typical stress-strain curves for a Gilsocarbon test specimen undergoing compressive loading. Two curves are recorded; black indicates compression behaviour measured parallel to the axis of compression $(x)$, and red shows the equivalent growth perpendicular to the compression axis (y). The blue points indicate the positions when time of flight measurements were carried out. Strains were collected using strain gauges.

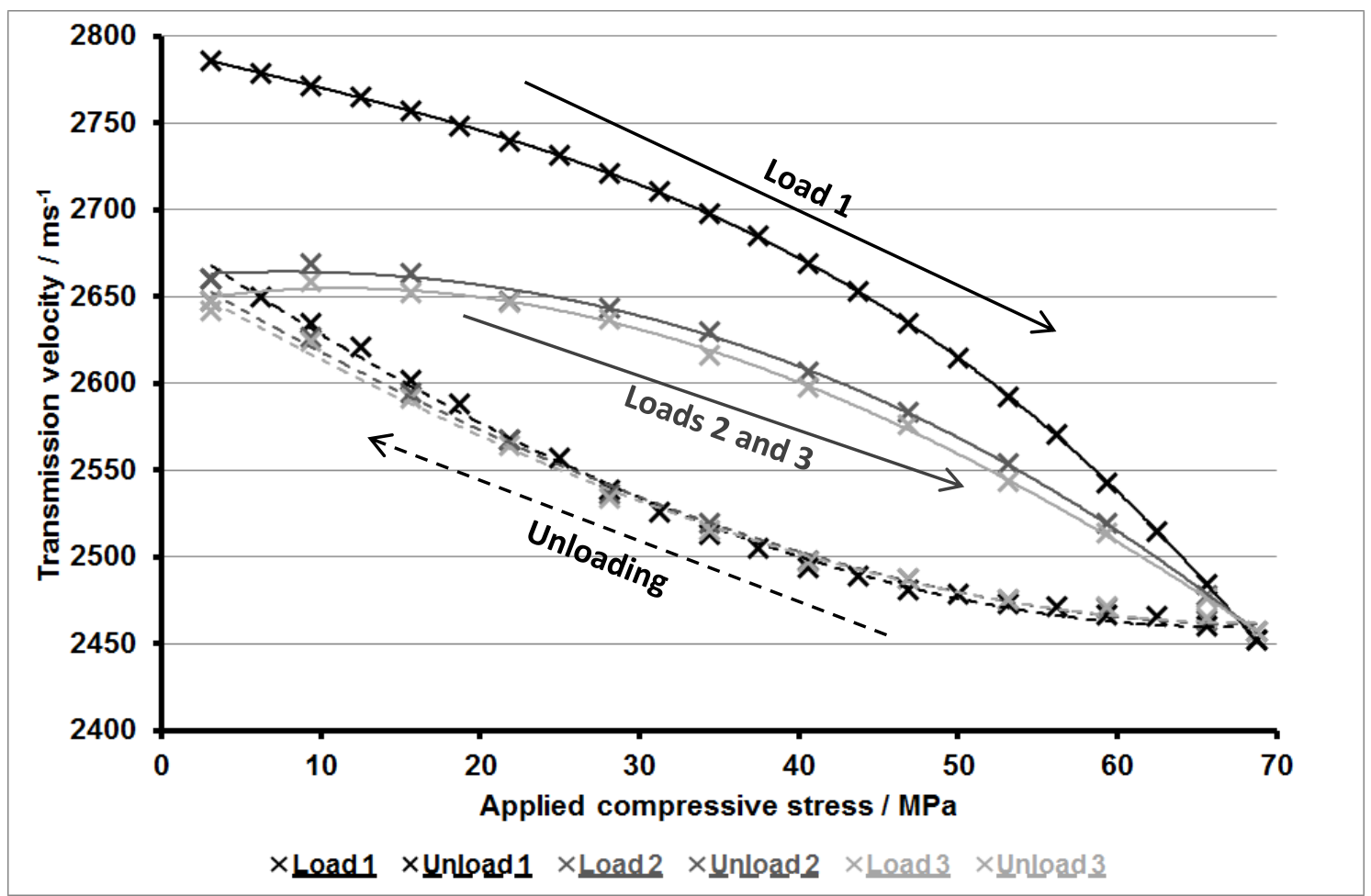

Figure 6. Measured ultrasonic transmission velocity along the axis of compression for a sample of Gilsocarbon under compressive load. Solid lines denote loading and dashed lines unloading. The first loading cycle is in black, the second in dark grey and the final in light grey. 


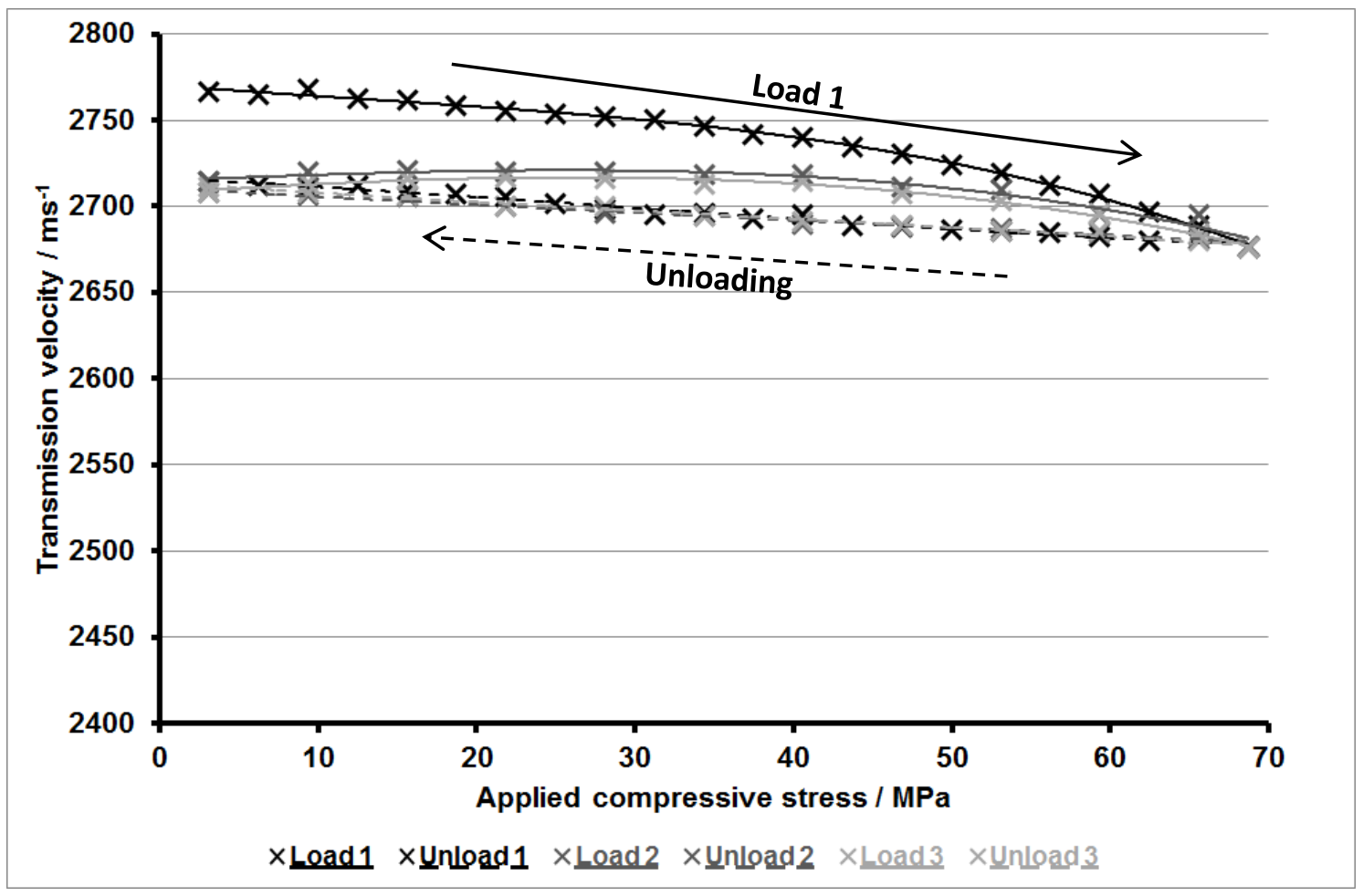

Figure 7. Measured ultrasonic transmission velocity perpendicular to the axis of compression for a sample of Gilsocarbon under compressive load. Solid lines denote loading and dashed lines unloading. The first loading cycle is in black, the second in dark grey and the final in light grey.

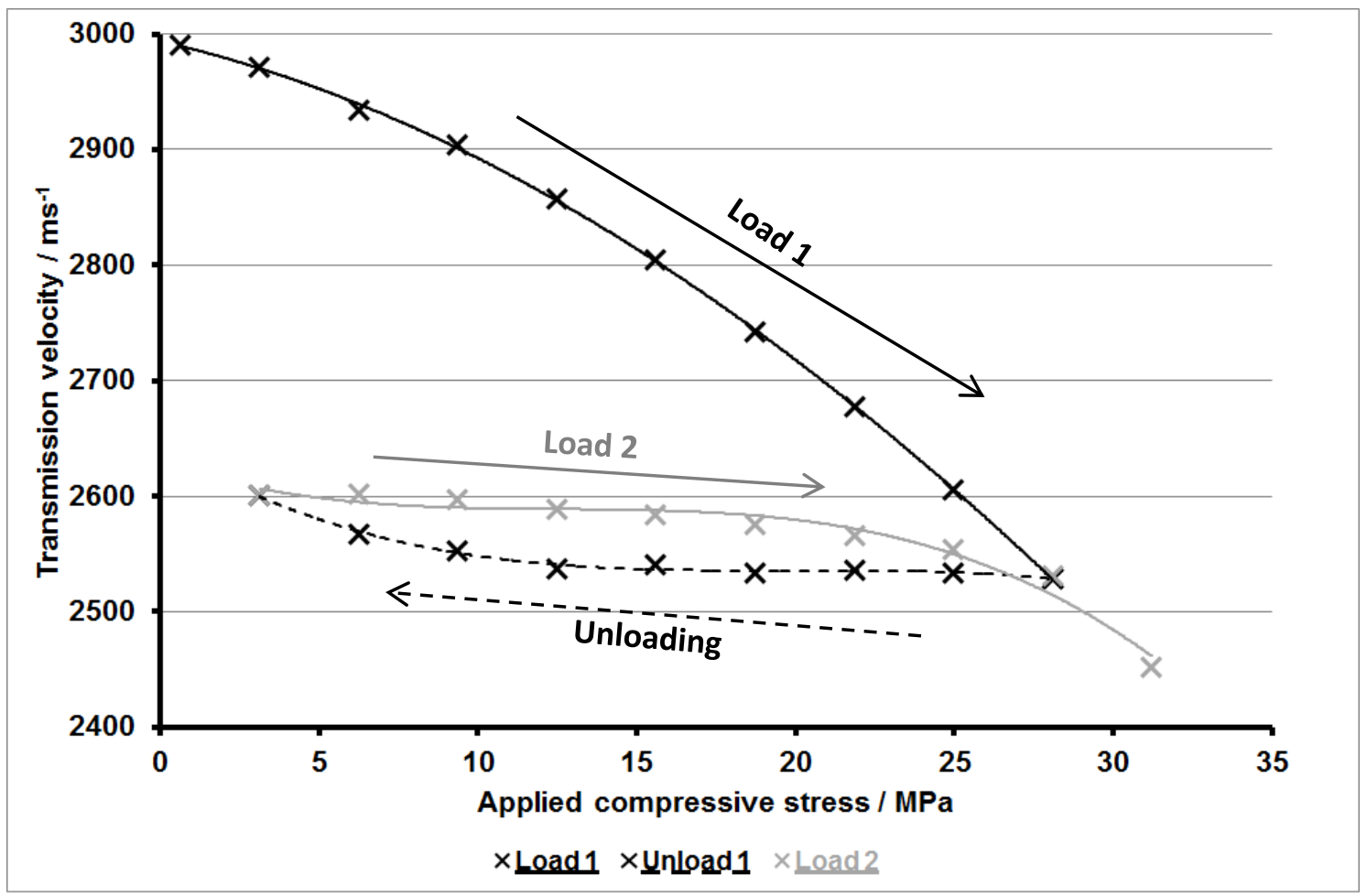

Figure 8. Change in axial transmission velocity with compressive load for a sample of PGA compressed with grain (i.e. along the axis of extrusion). 


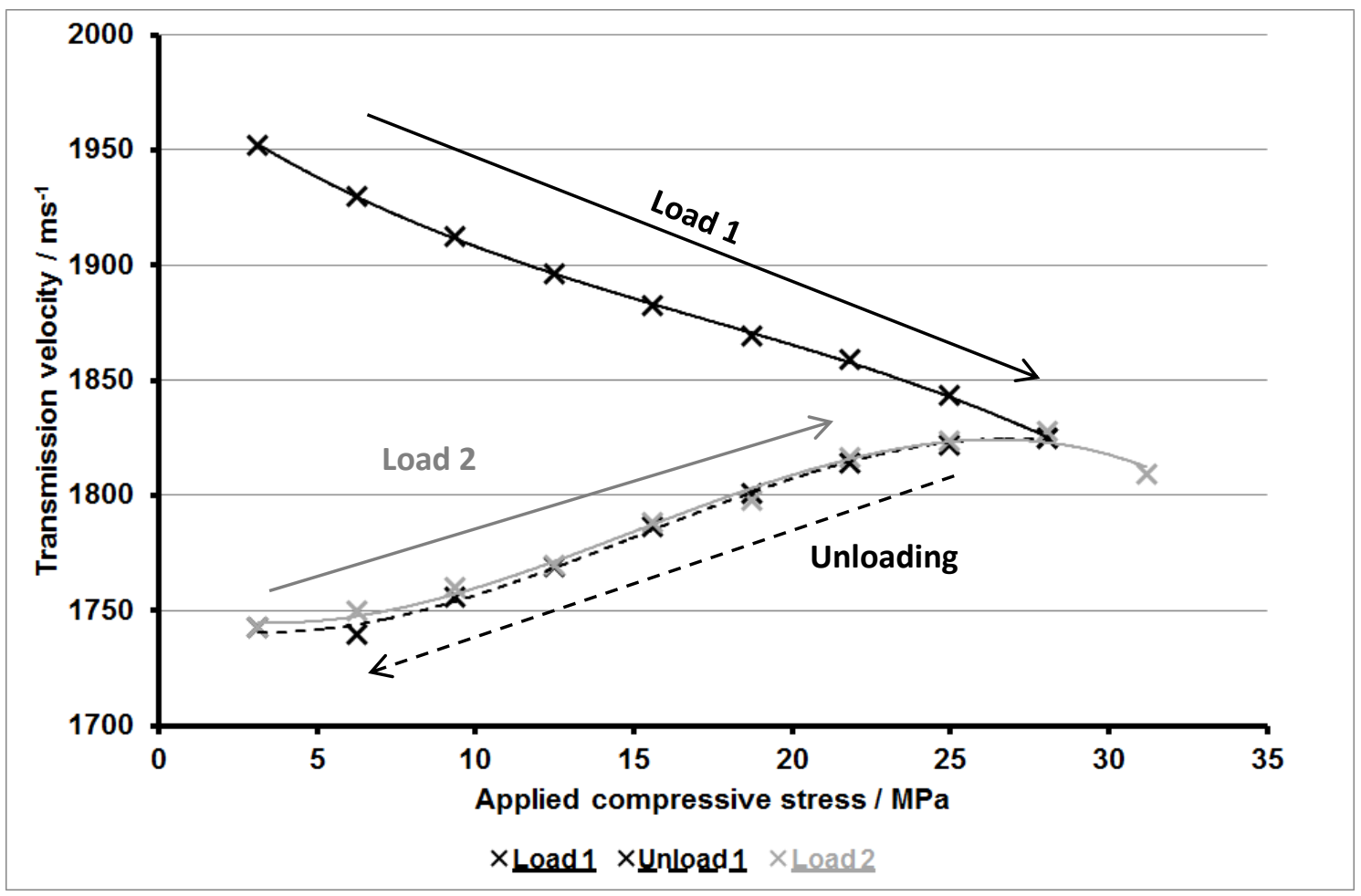

Figure 9. Change in axial transmission velocity with compressive load for a sample of PGA compressed against grain (i.e. perpendicular to the extrusion direction).

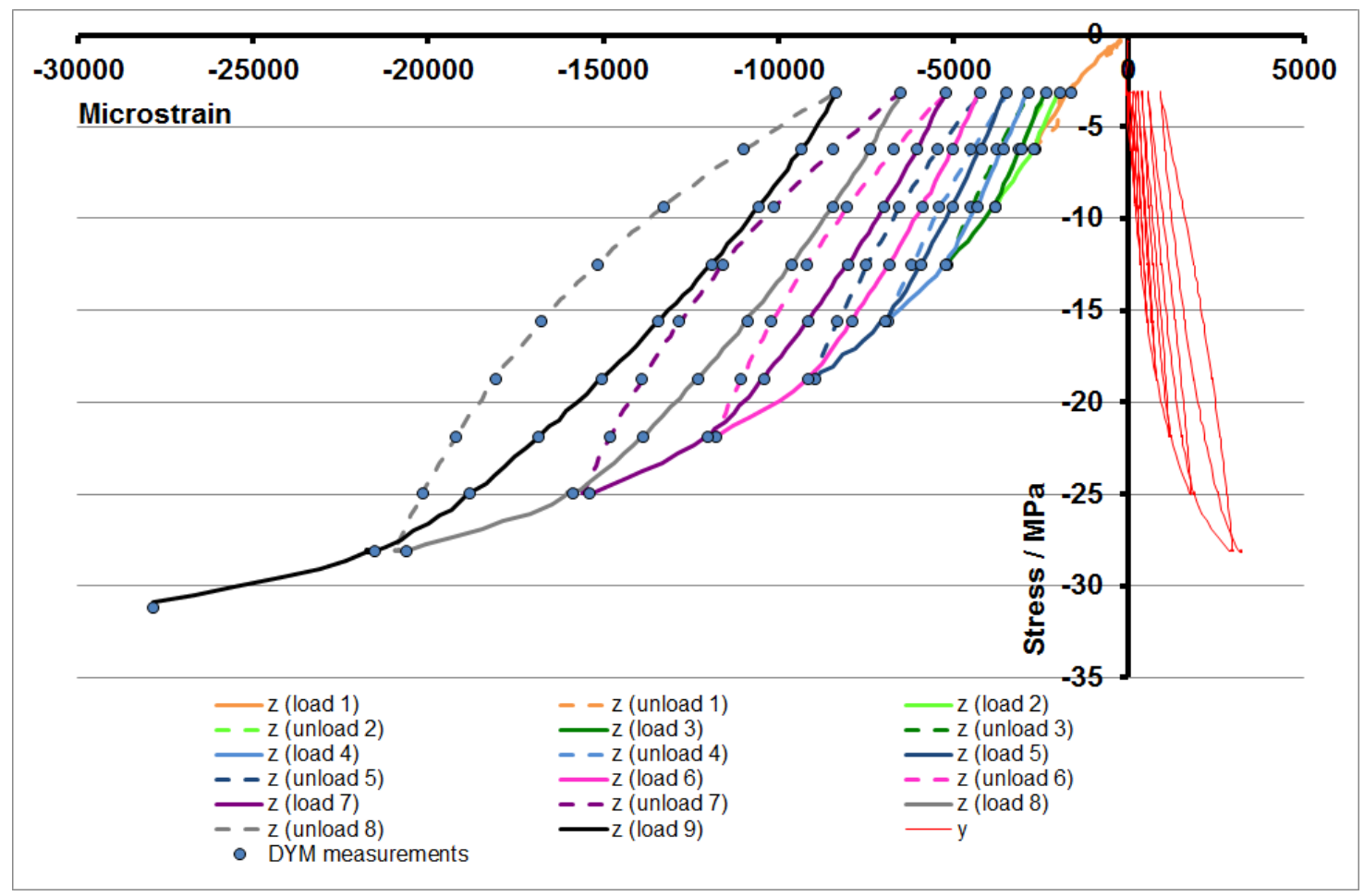

Figure 10. Stress-strain curve for PGA loaded against grain (the z-axis); a similar loading setup to that shown in Figure 9. The red line shows the stress-strain data for the $y$-axis, the orthogonal againstgrain direction (i.e. "with grain" is along the $x$-axis). 


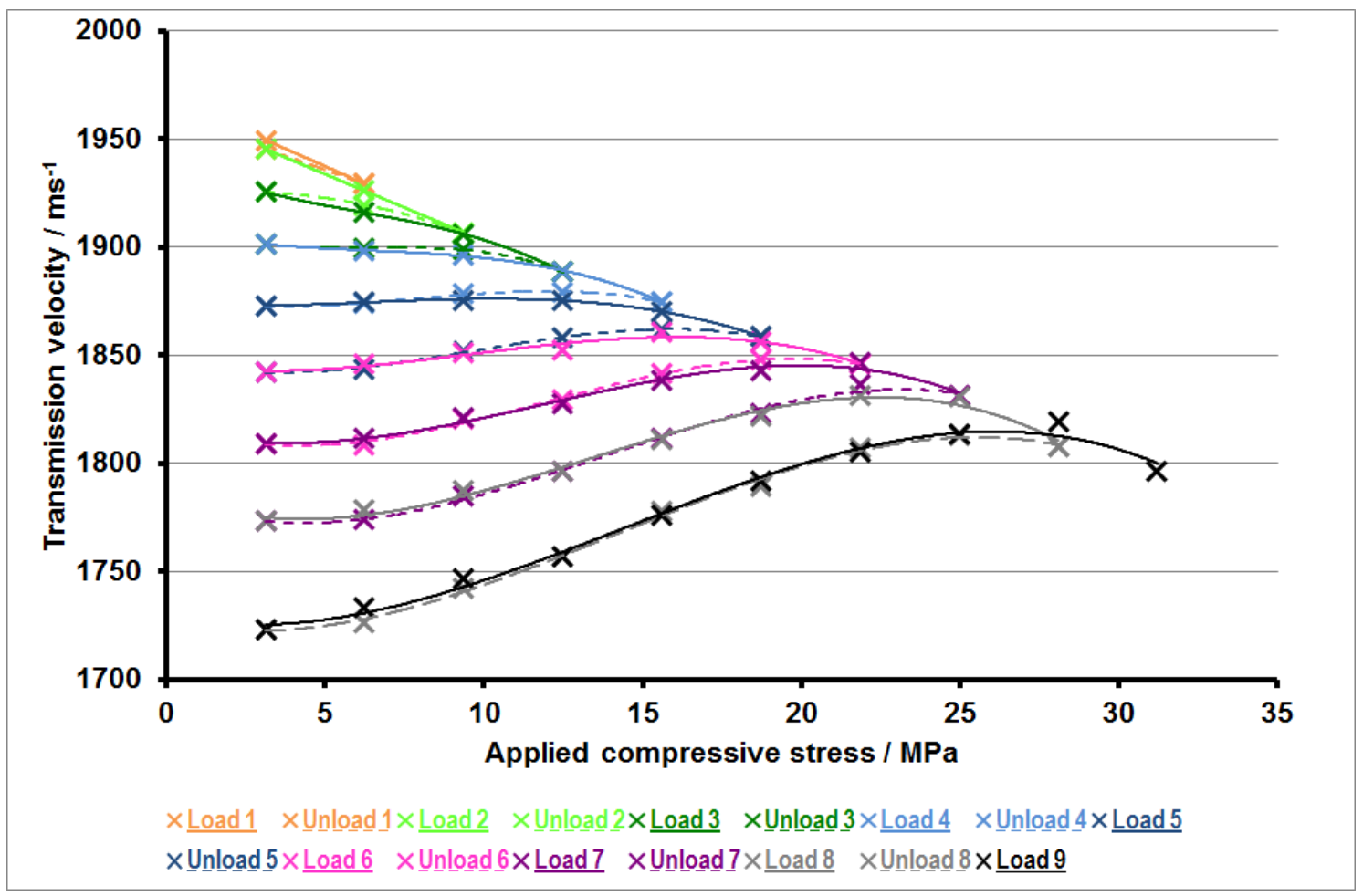

Figure 11. Change in axial transmission velocity with compressive load for the sample of PGA shown in Figure 10 compressed against grain (i.e. against the extrusion direction).

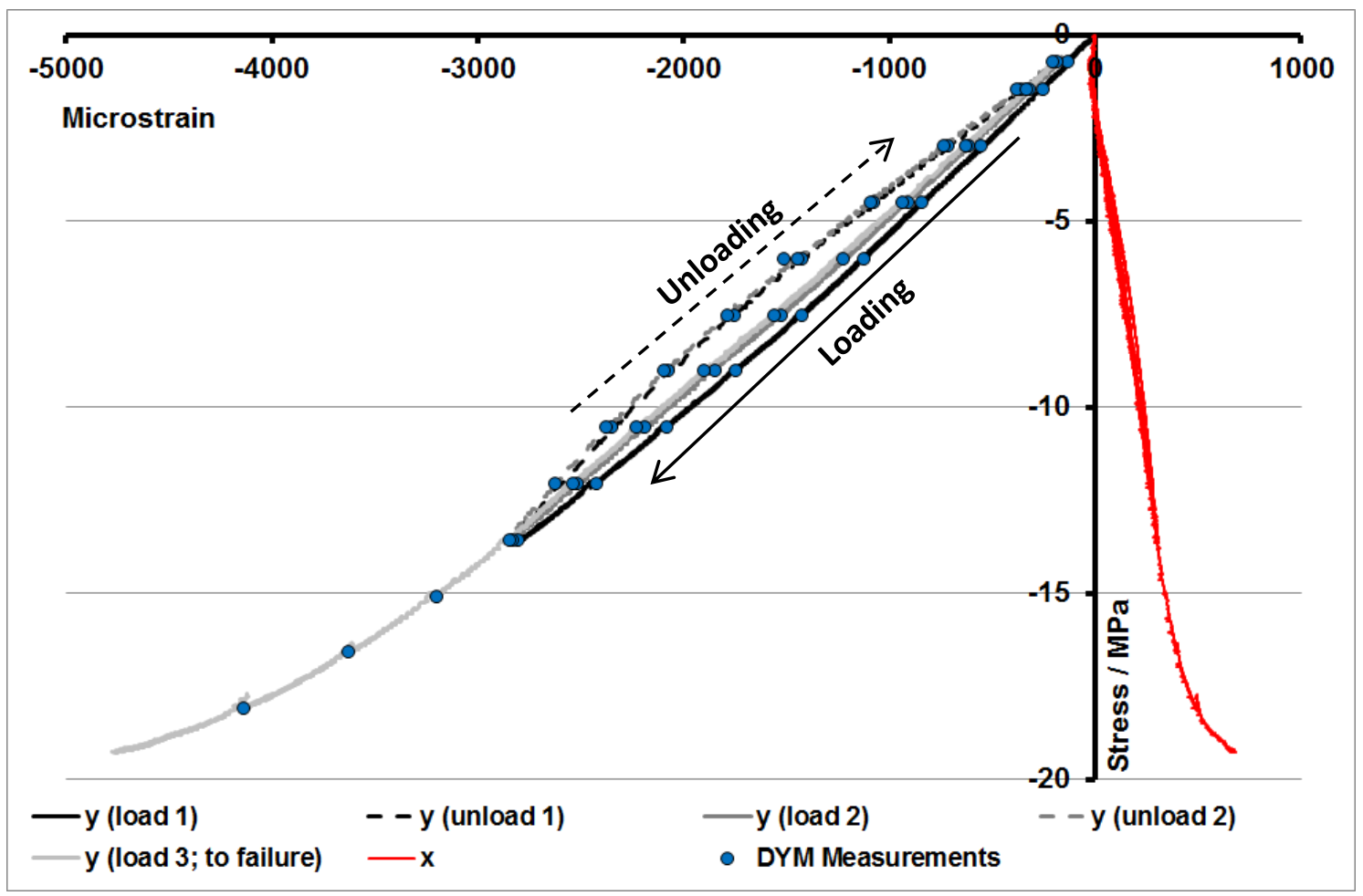

Figure 12. Stress-strain data for an irradiated PGA sample compressed against grain (along $y$ ); the $x$-axis denotes the with grain extrusion direction. 


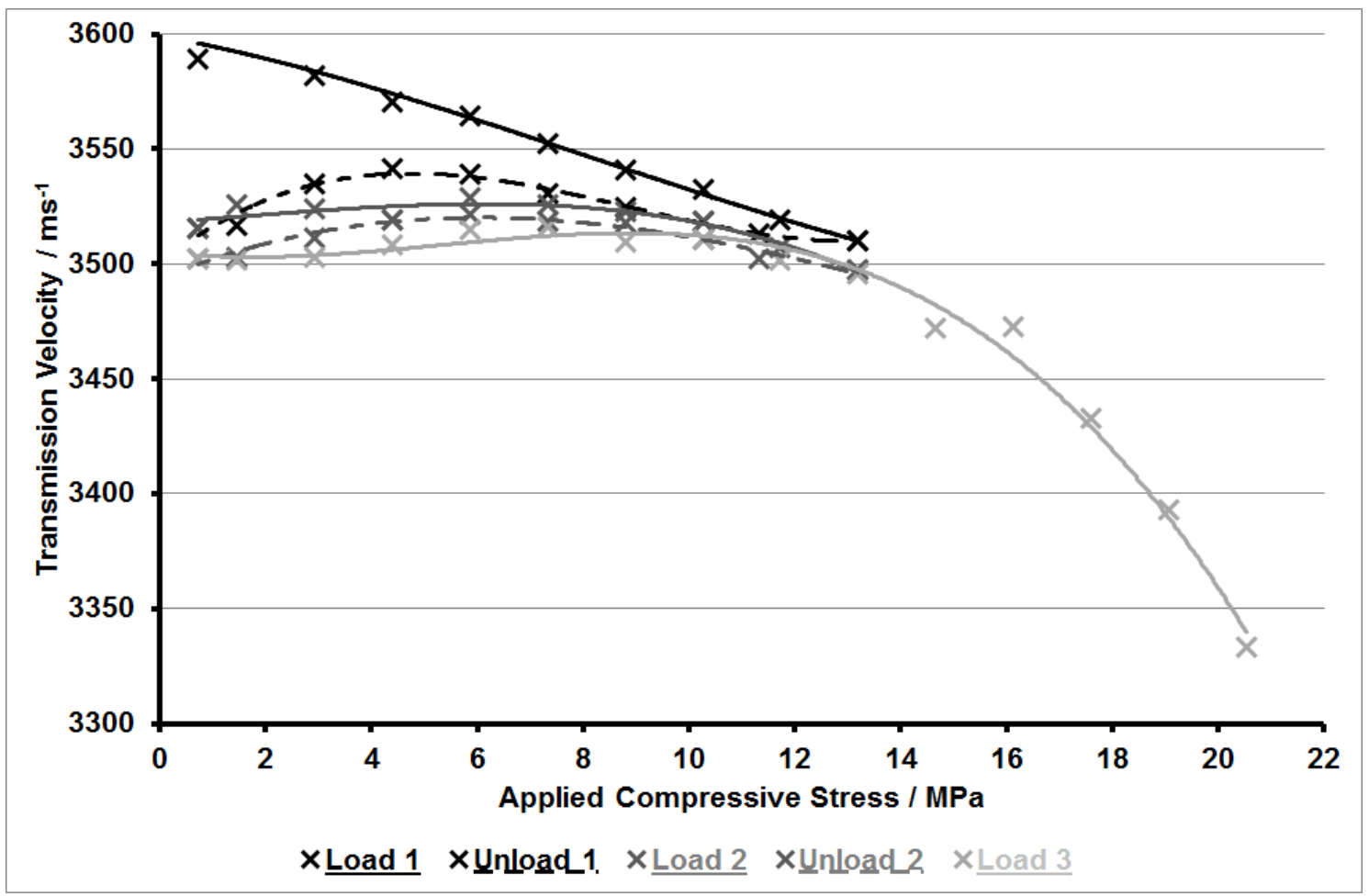

Figure 13. Change in axial transmission velocity with compressive load for irradiated PGA compressed with grain.

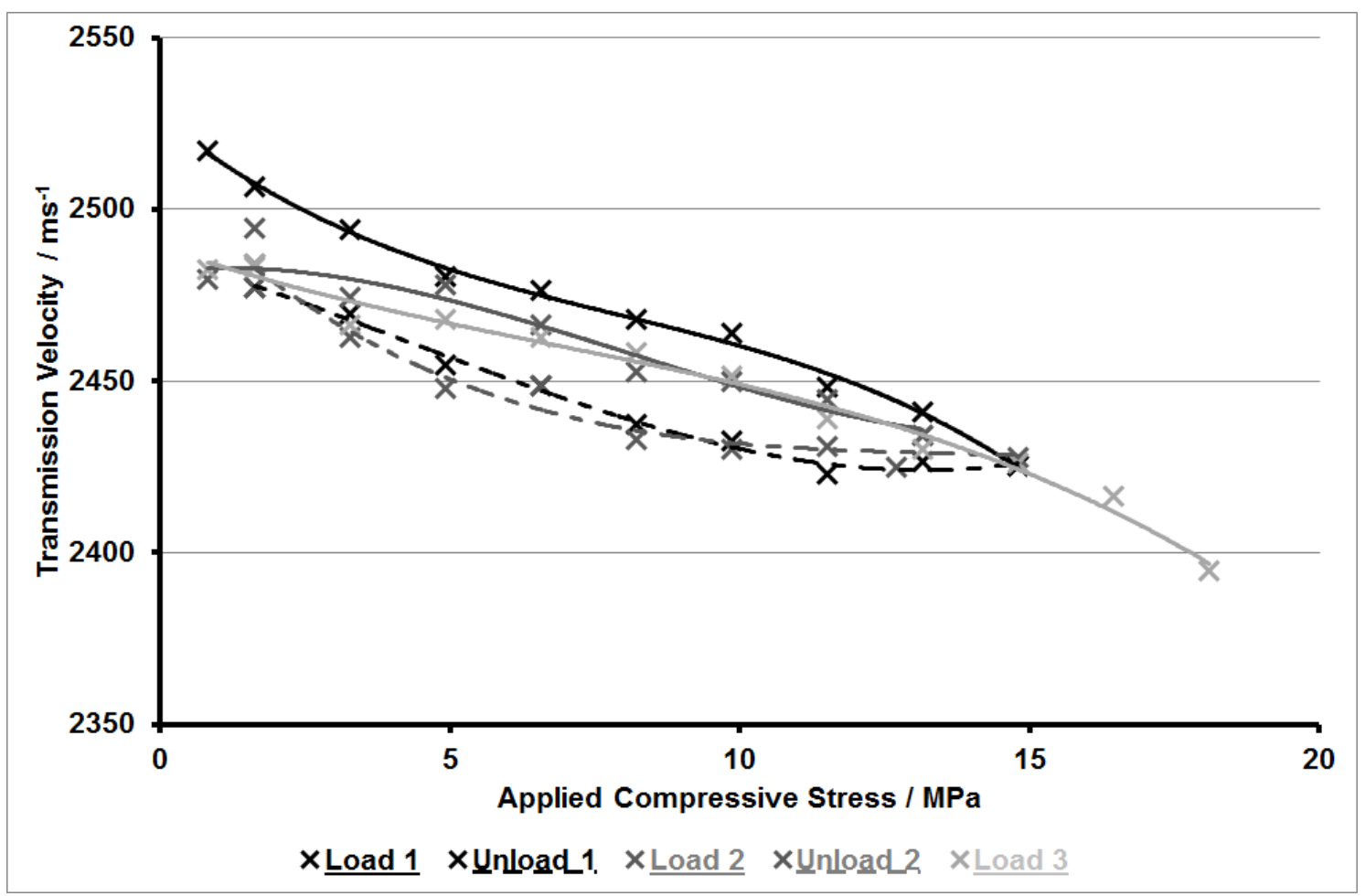

Figure 14. Change in axial transmission velocity with compressive load for irradiated PGA compressed against grain. 


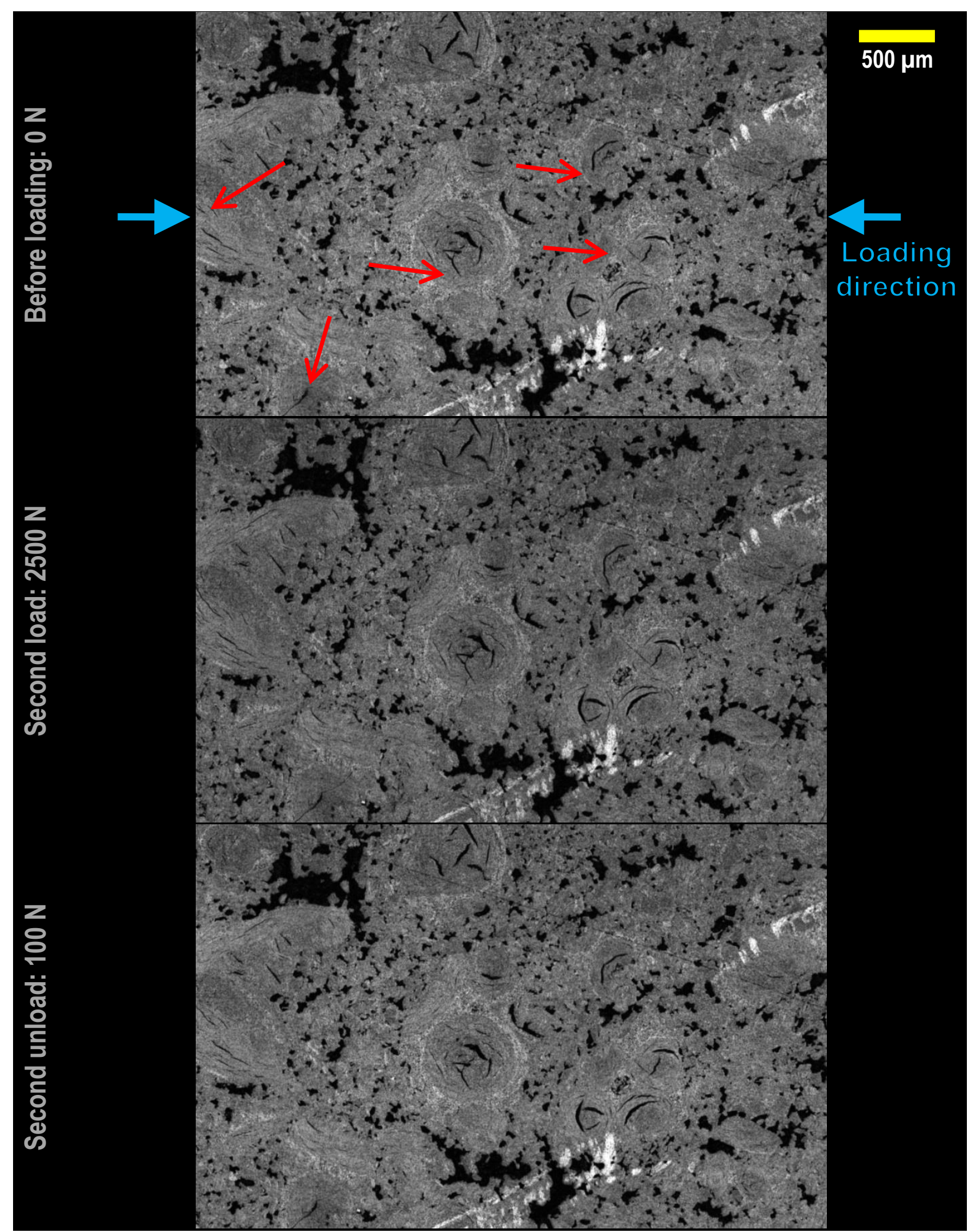

Figure 15. Magnified regions from selected micrographs from the second load/unload cycle of a typical Gilsocarbon sample. 


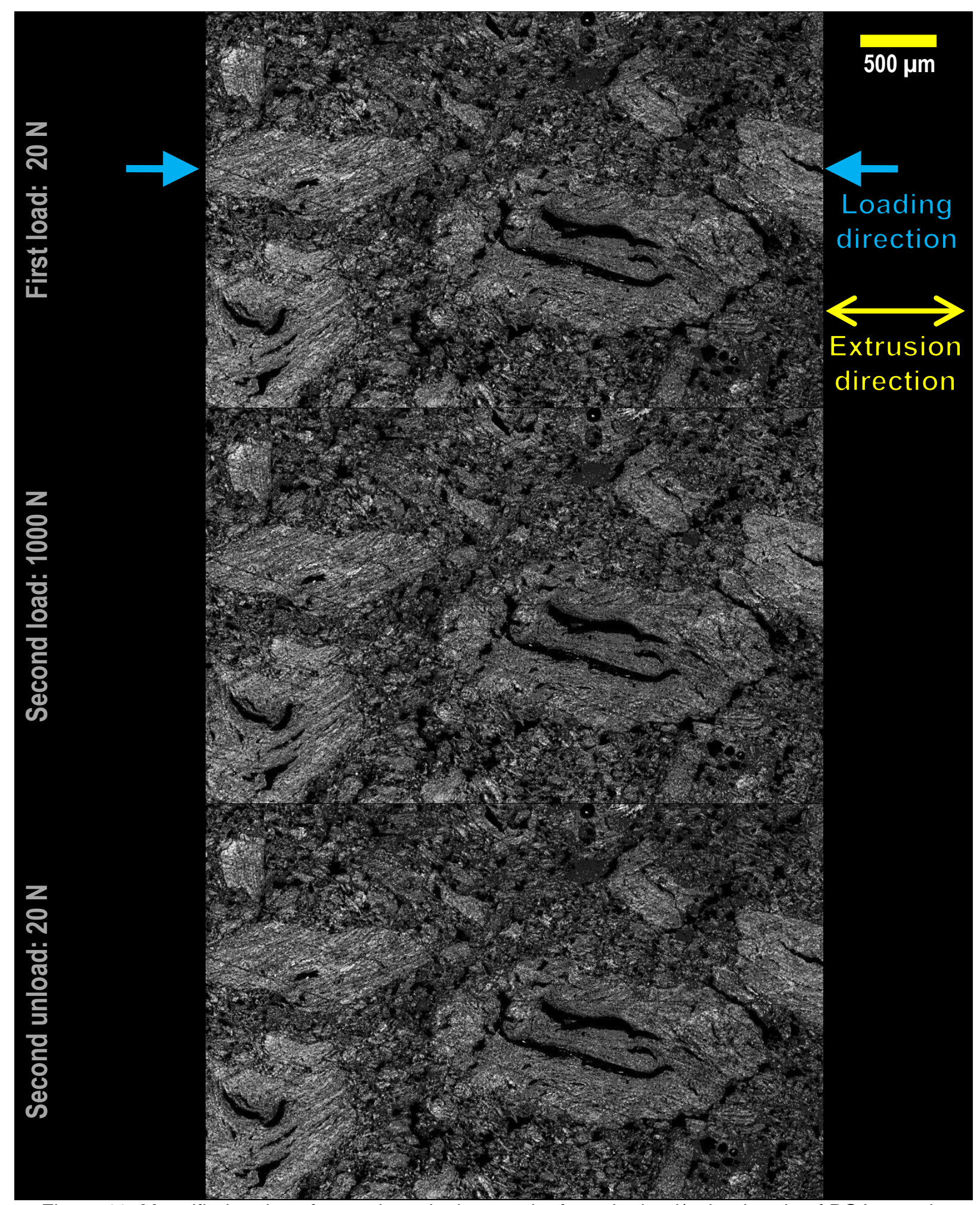

Figure 16. Magnified regions from selected micrographs from the load/unload cycle of PGA sample compressed with grain. The grain direction for this specimen is along the sample length (i.e from left to right). 


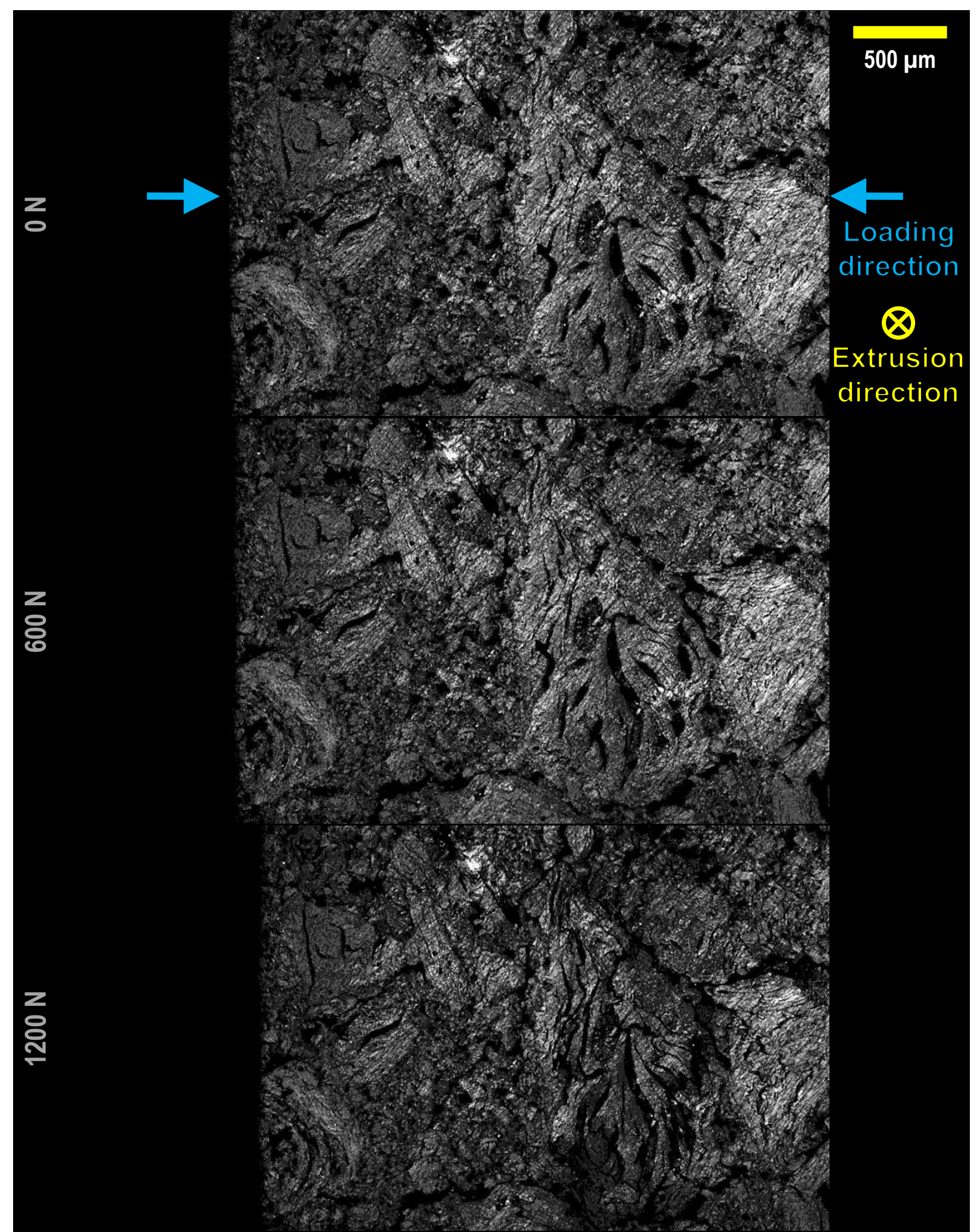

Figure 17. Magnified regions from selected micrographs from PGA sample loaded against grain. The grain direction for this specimen is along the sample height (i.e. into the page). 


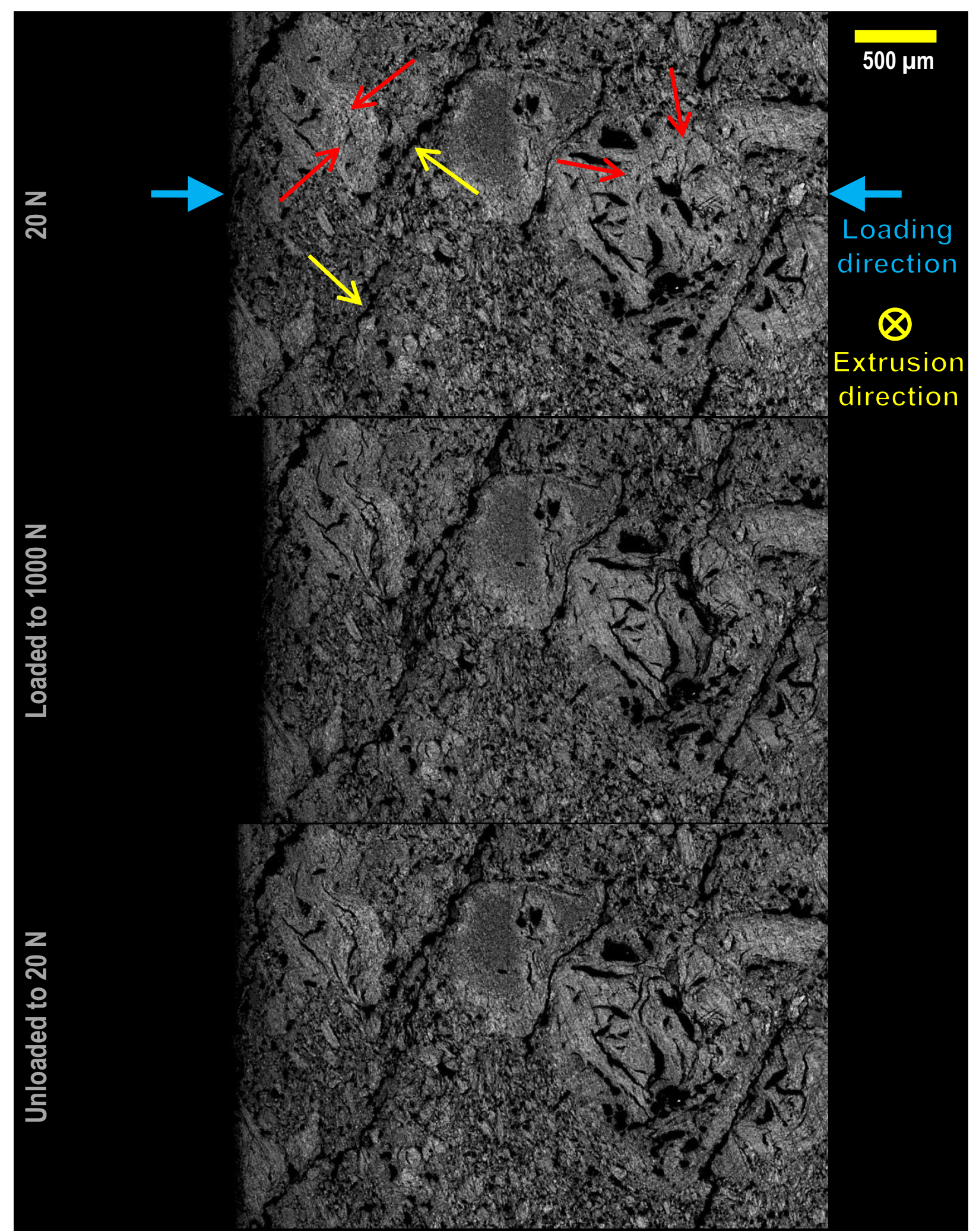

Figure 18. Magnified regions from selected micrographs from the load/unload cycle of PGA compressed against grain. The grain direction for this specimen is along the sample height (into the page). Red arrows indicate areas of significant crack initiation as the specimen is loaded. Yellow show regions of indigenous porosity which are sensitive to compressive load. 


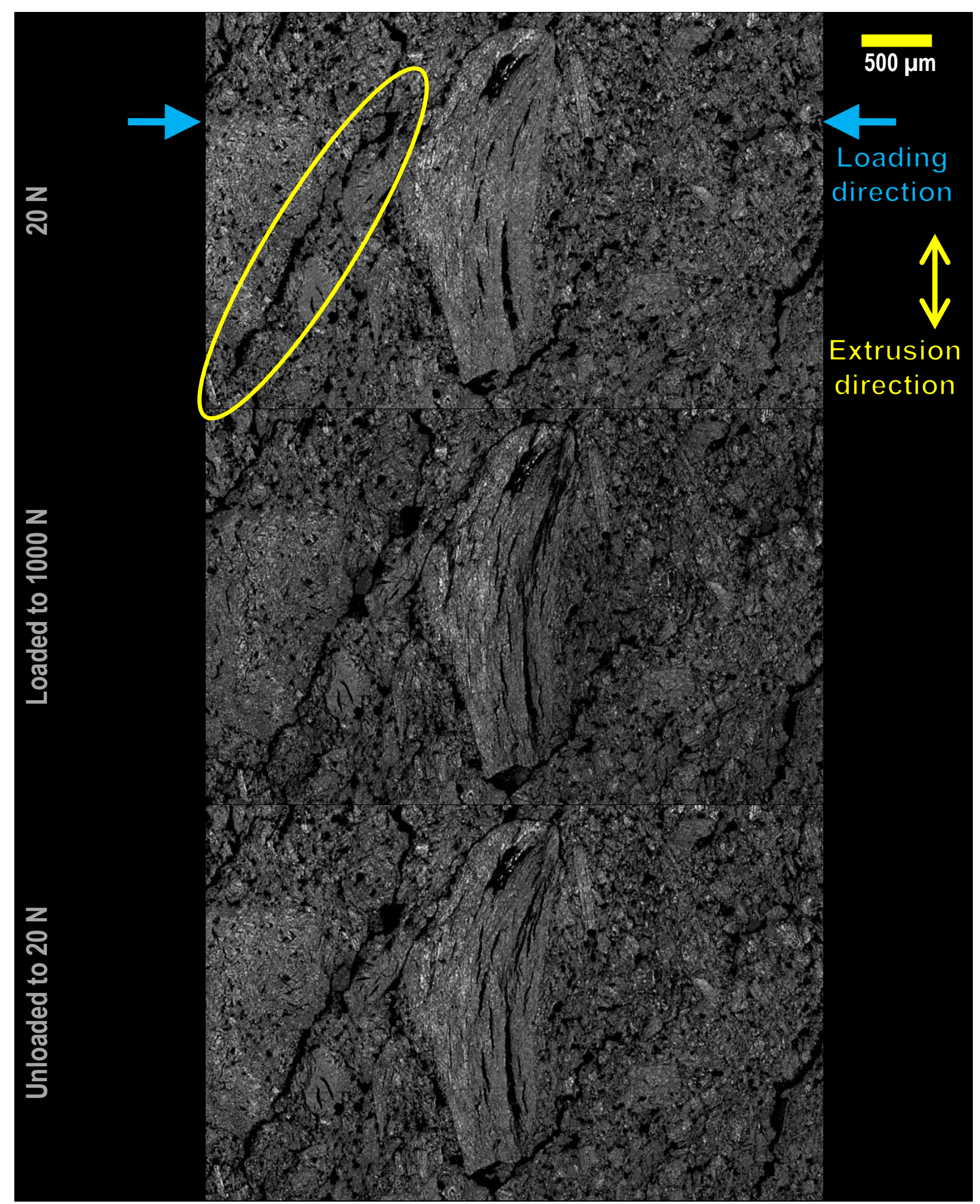

Figure 19. Magnified regions from selected micrographs from the load/unload cycle of PGA sample compressed against grain. The grain direction for this specimen is along the sample width (i.e. top to bottom). The circle highlights an example of porosity which closes with applied compressive load. 


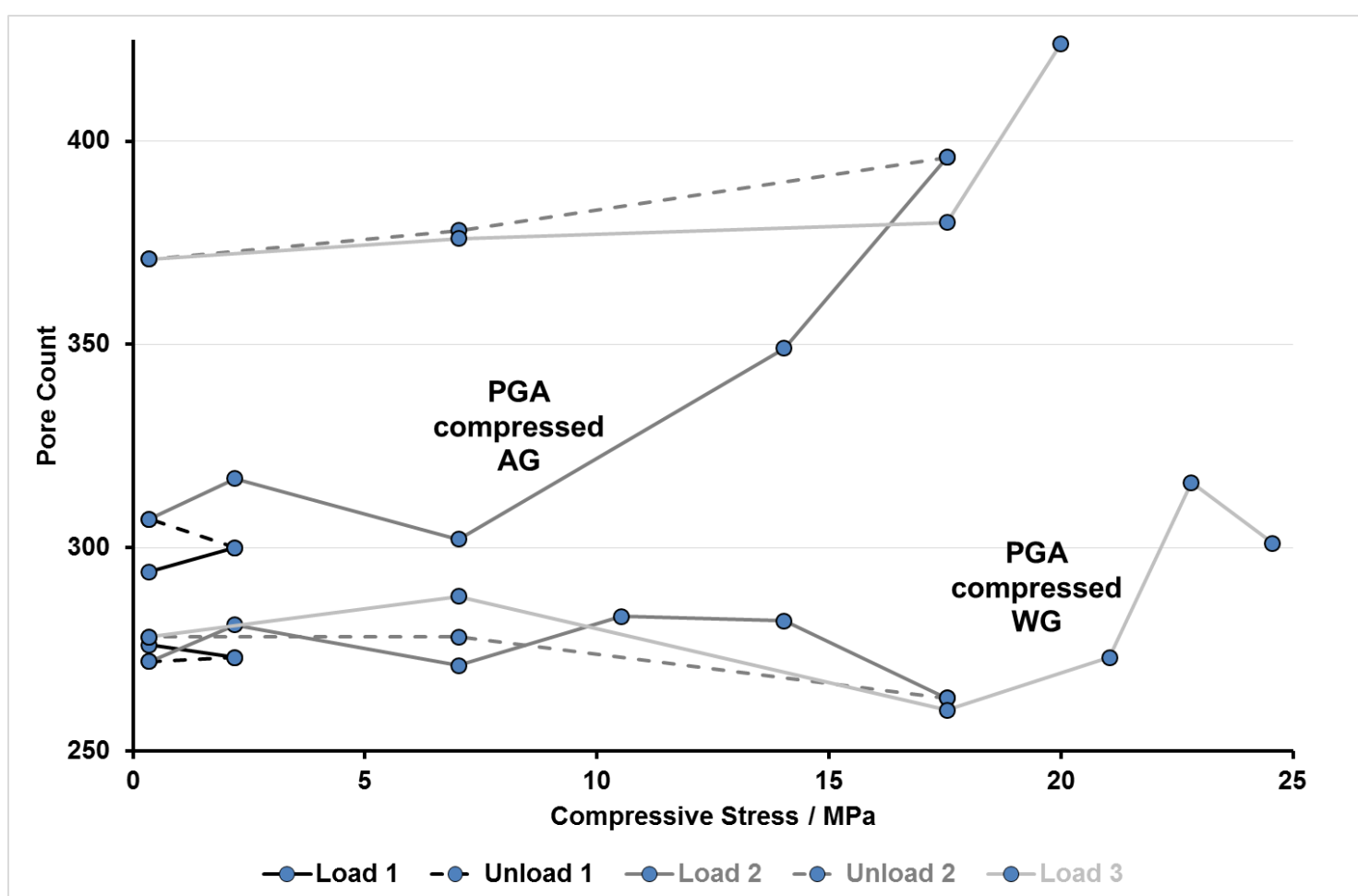

Figure 20. Plot showing the number of pores detected from micrographs of specimens during loading and unloading of with grain (WG) and against grain (AG). The blue circles indicate positions where micrographs were collected.

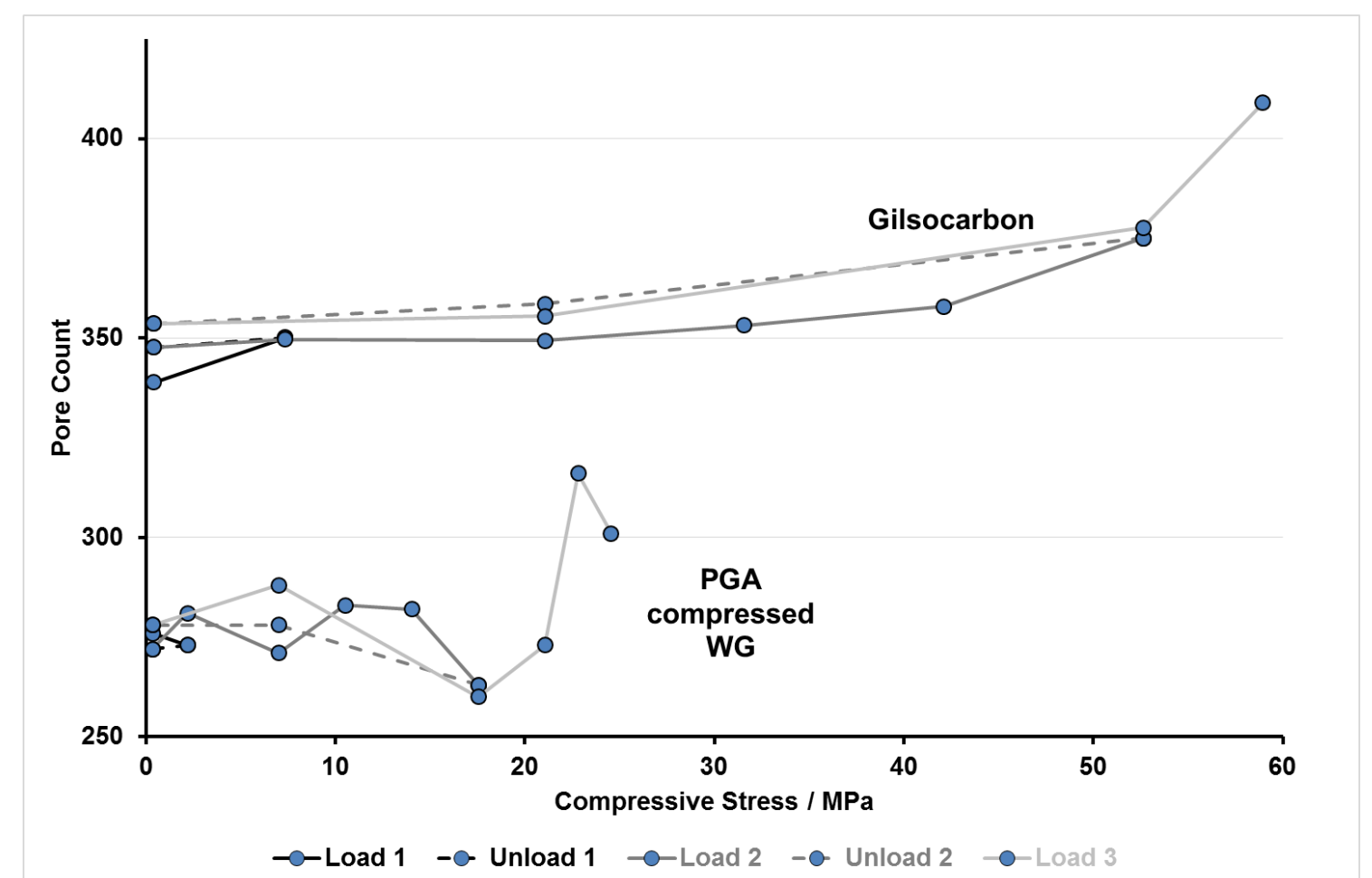

Figure 21. Previous plot (Figure 20) with the addition of Gilsocarbon pore data, plotted on a separate graph and with PGA compressed against grain omitted for clarity. 


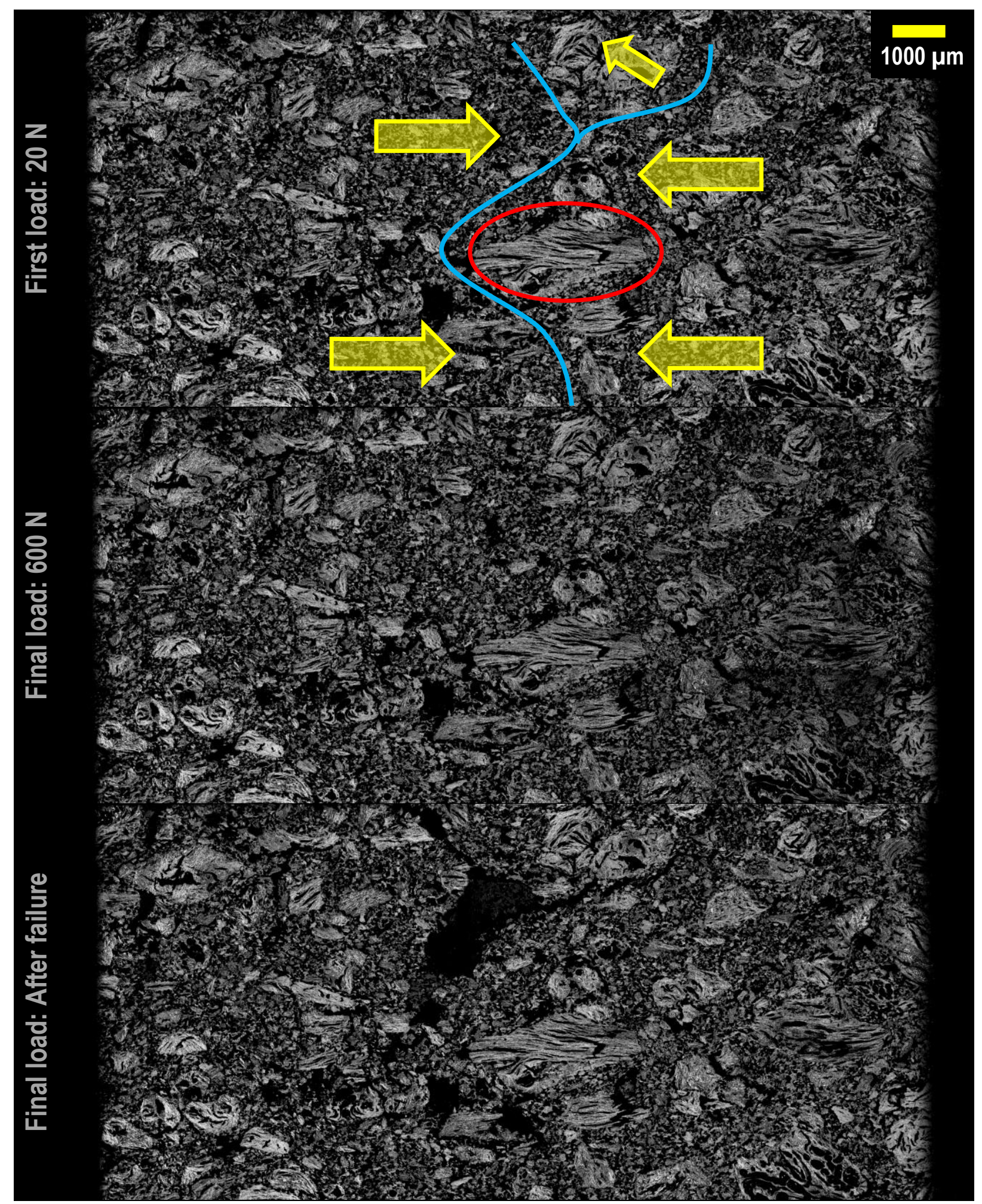

Figure 22. Selected micrographs from the load/unload cycle of irradiated PGA sample compressed with grain. The grain direction for this specimen is along the sample length from left to right. The red circle highlights a filler particle which undergoes very little change during the loading. The blue lines indicate the fault lines along which the sample fails with individual plates moving in the direction of the arrows. 


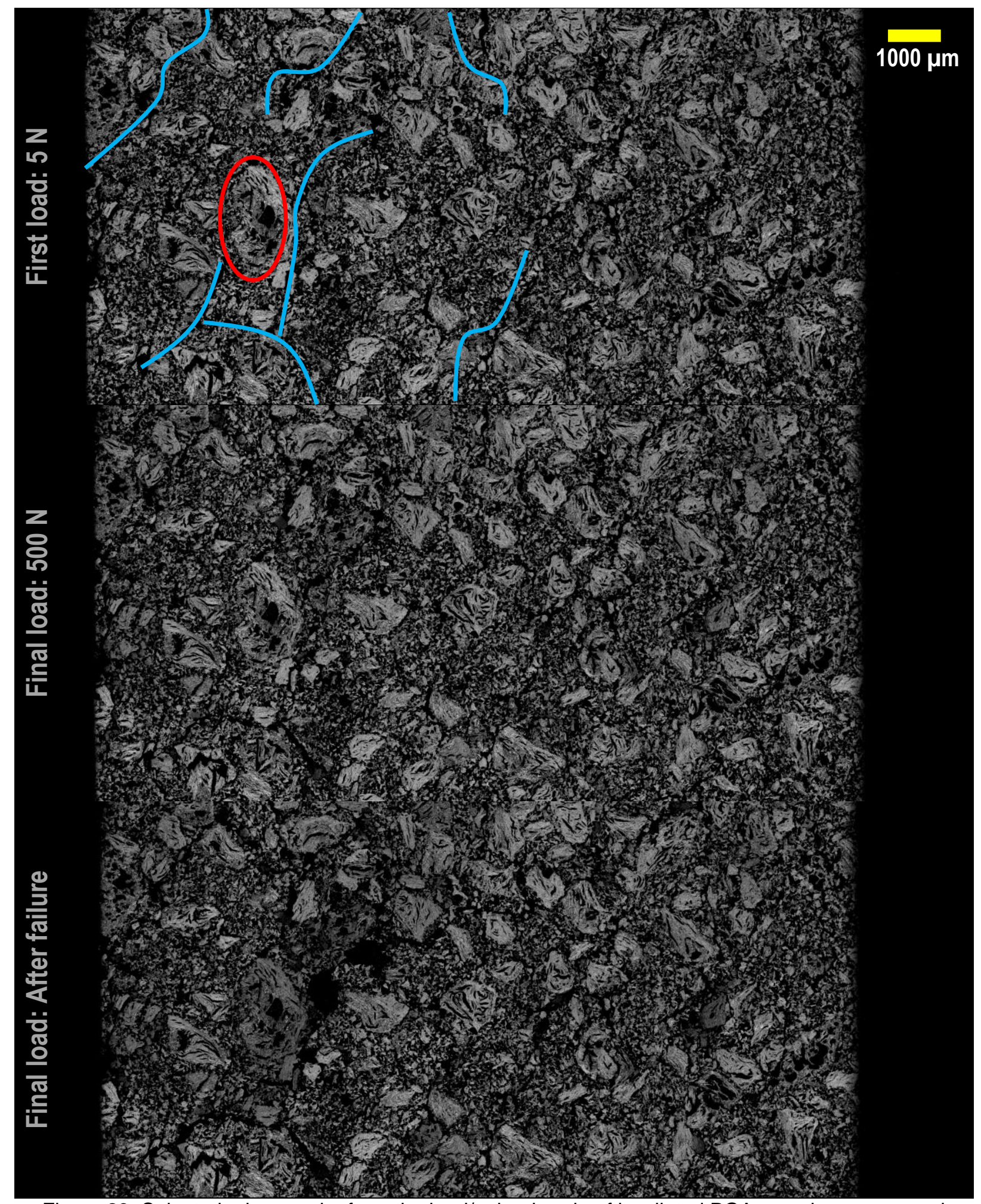

Figure 23. Selected micrographs from the load/unload cycle of irradiated PGA sample compressed against grain. Grain direction for this sample is along the sample height, (into the page). The red circle highlights a filler particle which undergoes little to no deformation; in contrast to the unirradiated equivalent. As before, the blue lines indicate the fault lines along which failure eventually occurs.

\section{References}


[1] B. Marsden and G. Hall, "Graphite in Gas-Cooled Reactors," in Comprehensive Nuclear Materials, Volume 4, Elsevier, 2012, pp. 325-390.

[2] W. P. Eatherly and E. L. Piper, "Manufacture," in Nuclear Graphite, New York and London, Academic Press, 1962, pp. 22-31.

[3] B. J. Marsden, M. Haverty, W. Bodel, G. Hall, A. N. Jones, P. M. Mummery and M. Treifi, "Dimensional Change, Irradiation Creep and Termal/Mechnical Property Changes in Nuclear Graphite," International Materials Reviews, vol. 61, no. 3, pp. 155-182, 2016.

[4] H. F. Kretchman, The Story of Gilsonite, Salt Lake City: American Gilsonite Company, 1967.

[5] B. Rand, "Mechanical Properties," in Graphite and Precursors, P. Delhaes, Ed., Amsterdam, Gordon and Breach, 2001, p. 118.

[6] W. Bodel, The Relationship between Microstructure and Young's Modulus of Nuclear Graphite, Manchester: The University of Manchester, 2013.

[7] J. E. Brocklehurst and B. T. Kelly, "Analysis of the dimensional changes and structural changes in polycrystalline graphite under fast neutron irradiation," Carbon, vol. 31, no. 1, pp. 155-178, 1993.

[8] S. Yoda, M. Eto and T. Oku, "Change in dynamic Young's modulus of nuclear-grade isotropic graphite during tensile and compressive stressing," Journal of nuclear materials, vol. 119, pp. 278-283, 1983.

[9] R. Taylor, R. G. Brown, K. Gilchrist, E. Hall, A. T. Hodds, B. T. Kelly and F. Morris, "The Mechanical Properties of Reactor Graphite," Carbon, vol. 5, pp. 519-531, 1967.

[10] J. V. Best, W. J. Stephen and A. J. Wickham, "Radiolytic Graphite Oxidation," Progress in Nuclear Energy, vol. 16, pp. 127-178, 1985.

[11] British Standards Institute, BS-EN-843-2:2007 Advanced Technical Ceramics - Part 2: Determination of Young's modulus, shear modulus and Poisson's ratio, 2007.

[12] ASTM, Measuring sonic velocity in obtaining Young's modulus, ASTM C769 - 09.

[13] J. E. Brocklehurst, "Fracture in Polycrystalline Graphite," in Chemistry and Physics of Carbon, New York, Marcel Dekker, 1977, pp. 145-272.

[14] J. E. Taylor, G. N. Hall and P. M. Mummery, "Investigating the effects of stress on the pore structures of nuclear grade graphites," Journal of Nuclear Materials, vol. 470, pp. 216-228, 2016.

[15] P. J. Heard, M. R. Wooton, R. Moskovic and P. E. Flewitt, "Deformation and fracture of irradiated polygranular pile grade A reactor core graphite," Journal of Nuclear Materials, vol. 418, pp. 223- 
232, 2011.

The authors would like to acknowledge the EPSRC for funding this research under grant EP/C537750. 